NBER WORKING PAPER SERIES

THE NEW SCIENCE OF PLEASURE

Daniel L. McFadden

Working Paper 18687

http://www.nber.org/papers/w18687

\author{
NATIONAL BUREAU OF ECONOMIC RESEARCH \\ 1050 Massachusetts Avenue \\ Cambridge, MA 02138 \\ January 2013
}

An initial version of this paper was presented as the Frisch Lecture, Econometric Society World Congress, London, 2005. This research was supported by the E. Morris Cox endowment at the University of California, Berkeley, and by the National Institute on Aging of the National Institutes of Health, grants P01AG005842, P01AG033559, and RC4AG039036. I am indebted to Sam Bowles, Colin Camerer, John Dagsvik, Ernst Fehr, Mogens Fosgerau, James Heckman, Danny Kahneman, David Laibson, Charles Manski, Rosa Matzkin, and Joachim Winter for useful comments. The views expressed herein are those of the author and do not necessarily reflect the views of the National Bureau of Economic Research.

NBER working papers are circulated for discussion and comment purposes. They have not been peerreviewed or been subject to the review by the NBER Board of Directors that accompanies official NBER publications.

(C) 2013 by Daniel L. McFadden. All rights reserved. Short sections of text, not to exceed two paragraphs, may be quoted without explicit permission provided that full credit, including $(\mathbb{C}$ notice, is given to the source. 
The New Science of Pleasure

Daniel L. McFadden

NBER Working Paper No. 18687

January 2013, Revised February 2013

JEL No. D03,D1

\begin{abstract}
$\underline{\text { ABSTRACT }}$
Economists since the days of Adam Smith and Jeremy Bentham have traditionally viewed consumers as driven by relentless and consistent pursuit of self-interest, with their choices in the marketplace providing all the measurements needed to reveal their preferences and assess their well-being. This theory of consumer choice is empirically successful, and provides the foundation for most economic policy. However, the traditional view is now being challenged by evidence from cognitive psychology, anthropology, evolutionary biology, and neurology. This paper begins by surveying the origins of neoclassical consumer choice theory and recent developments. Following this, it reviews the newer evidence on consumer behavior, and what this implies for the measurement of consumer choice behavior and well-being.
\end{abstract}

Daniel L. McFadden

University of California, Berkeley

Department of Economics

549 Evans Hall \#3880

Berkeley, CA 94720-3880

and NBER

mcfadden@econ.berkeley.edu 


\section{Contents}

I Introduction 1

II Pleasure, Pain, Utility 2

III First Measurements 9

IV The Stone Age 9

V Measurement of Well-Being $\quad 12$

$\begin{array}{lll}\text { VI Expansions } & 14\end{array}$

$\begin{array}{lll}\text { VI.1 Preference Heterogeneity } & 15\end{array}$

$\begin{array}{lll}\text { VI.2 Nonlinear Budget Sets } & 16\end{array}$

VI.3 Hedonic Goods and Household Production 17

$\begin{array}{ll}\text { VI.4 Consumer Dynamics } & 20\end{array}$

VII New Frontiers 23

VII.1 Stated Preferences and Conjoint Analysis 24

VII.2 Measurements from Cognitive Psychology 26

VII.3 The Sociality of Choice 29

$\begin{array}{lll}\text { VII.4 Sensation and Neuroeconomics } & 32\end{array}$

$\begin{array}{ll}\text { VIII The Future } & 37\end{array}$

$\begin{array}{ll}\text { References } & 38\end{array}$

Figures and Tables $\quad 45$ 


\title{
The New Science of Pleasure \\ Consumer Choice Behavior and the Measurement of Well-Being
}

\author{
Daniel McFadden
}

"Illusion, Temperament, Succession, Surface, Surprise, Reality, Subjectiveness - there are threads on the loom of time, these are the threads of life."

Ralph Waldo Emerson, Experience, 1844

"Let there be granted to the science of pleasure what is granted to the science of energy, to imagine an ideally perfect instrument, a psychophysical machine, continually registering the height of pleasure experienced by an individual, exactly according to the verdict of consciousness, or rather diverging therefrom according to a law of errors. From moment to moment the hedonimeter varies; the delicate index now flickering with the flutter of the passions, now steadied by intellectual activity, low sunk whole hours in the neighbourhood of zero, or momentarily springing up toward infinity.”

Francis Y. Edgeworth, Mathematical Psychics, 1881

\section{Introduction}

At the base of economic analysis is the consumer, whose behavior and well-being motivate a whole gauntlet of questions spanning demand analysis, incentive theory and mechanism design, project evaluation, and the introduction and marketing of private and public goods and services. Understanding and modeling consumer welfare was central in early economics, and remains so, with a continuing tension between elements of illusion, temperament, and subjectivity in consumer behavior, and the need for stable, predictive indicators for choice and well-being. The neoclassical model of the individualistic utility-maximizing consumer that forms the basis of most economic analysis is largely a finished subject, but new studies of consumer behavior and interesting new measurements challenge this model. This behavioral revaluation suggests new directions for the continuing development of choice theory.

This paper surveys the history of the study of consumer behavior and well-being, with particular attention to the lessons and opportunities afforded by new measurements coming into economics from cognitive psychology, anthropology, market science, and neurology. This paper will focus on the perceptions, emotions, and behavior of individual consumers, and touch only briefly on important related issues of interpersonal comparisons and economic policy evaluation. I will start with the views of the classical economists on happiness and utility. I will discuss first attempts at measurement, followed by the flowering of demand analysis in the age of Sir Richard Stone. I will then turn to expansions of neoclassical demand measurement, particularly to the subjects of choice in non-linear and discrete budget sets, and finally to the new frontiers of measurement shared by economics and other disciplines. 


\section{Pleasure, Pain, Utility}

Systematic study of consumer motivation and well-being started with Jeremy Bentham, who still sits, stuffed, in University College London, and to this day is reputed to be the life of any party of economists that he joins. In Introduction to the Principles of Morals and Legislation, published in 1789, Bentham laid out the concept of consumers driven by self-interest to increase pleasure and reduce pain: "My notion of man is that ... he aims at happiness ... in every thing he does.” Bentham and his successors explored the economic implications and moral content of utilitarianism, but despite their quantitative rhetoric, they were not much concerned with the actual measurement of happiness. It is not that they considered utility unmeasurable. Quite the opposite: by introspection utility existed, and its practical measurement was not needed for drawing out the broad principles of utilitarianism. Choice was viewed as an automatic consequence of self-interest, not as behavior that could put utilitarianism to test. Pursuit of happiness explained everything, and predicted nothing. A comment by Frank Taussig (1912), at the end of the classical era, summarizes nicely the utilitarian attitude:

\footnotetext{
"An article can have no value unless it has utility. No one will give anything for an article unless it yield him satisfaction. Doubtless people are sometimes foolish, and buy things, as children do, to please a moment's fancy; but at least they think at the moment that there is a wish to be gratified. Doubtless, too, people often buy things which, though yielding pleasure for the moment, or postponing pain, are in the end harmful. But here ... we must accept the consumer as the final judge. The fact that he is willing to give up something in order to procure an article proves once for all that for him it has utility it fills a want."
}

The writings of the utilitarians provide insight into the nature and dimensions of well-being, and the problem of its measurement. Bentham thought about the pursuit of happiness in ways that did not fit into the later neoclassical synthesis, but which resonate with contemporary behavioral studies. Bentham's utility was attached to the experience or sensation that objects and actions produced, their pleasure-increasing or pain-reducing effect. Later, utility became identified with a state of being, with the consequences of actions rather than the processes producing these consequences. The behavioral revaluation supports the earlier view that attaches utility to process rather than to consequence. Bentham almost always distinguished increased pleasure and reduced pain as two distinct sources of happiness. This may just have been his penchant to say anything worth saying more than once, but perhaps he recognized that people respond differently to perceived gains and losses, a view supported by contemporary brain science.

Bentham laid out four critical dimensions that determine the utility of an experience: intensity, duration, certainty or uncertainty, and propinquity or remoteness. Clearly, Bentham's first two dimensions anticipated the utility of an episode as an integral of intensities over some time interval, although formalization of that idea would not come until Francis Edgeworth a century later. The third dimension anticipated a utility theory for risky prospects, and the fourth, intertemporal preferences and discounting. Also clearly present in classical economics 
are allowances for reciprocity and altruism in the determination of happiness. Bentham (1789) stressed the role of reciprocity:

"By the self-regarding principle, the more urgent the need a man feels himself to have of the kindness and good will of others, the more strenuous and steady will be his exertion for the obtaining it. ... The stronger a man's need of the effective benevolence of others, the stronger the inducement he has for the manifesting effective benevolence as towards them.”

Adam Smith (1753) noted the importance of altruism, particularly within families,

"How selfish soever man may be supposed, there are evidently some principles in his nature, which interest him in the fortune of others, and render their happiness necessary to him, though he derives nothing from it, except the pleasure of seeing it."

"Every man feels [after himself, the pleasures and pains] of the members of his own family. Those who usually live in the same house with him, his parents, his children, his brothers and sisters, are naturally the objects of his warmest affections. "

Edgeworth (1881) noted ways in which such altruism is reflected in behavior:

"... efforts and sacrifices ... are often incurred for the sake of one's family rather than oneself. The action of the family affections 'has always been fully reckoned with by economists', especially in relation to the distribution of the family income between its various members, the expenses of preparing children for their future career, and the accumulation of wealth to be enjoyed after the death of him by whom it has been earned."

Classical economics came slowly to the problem of recovering utility from observed behavior, Adam Smith (1776) described how "haggling and bargaining in the market” would achieve "rough equality" between value in use and value in exchange. Working at the fringes of mainstream economics, Jules Dupuit (1844) and Hermann Gossen (1854) deduced that consumers exhibiting diminishing marginal utility would achieve maximum utility by equalizing the marginal utility per unit of expenditure across various goods. Dupuit was remarkably prescient, recognizing that an individual demand curve can be identified with a marginal utility curve for a good, provided the marginal utility of money remained constant, and showing that the area behind the demand curve then gave a measure of “relative utility”, or in Marshall's later terminology, consumer surplus.

\section{FIGURE 1 ABOUT HERE}

Dupuit's idea of solving the inverse problem, recovering utility from demand, was brought into the mainstream at the end of the $19^{\text {th }}$ century by William Stanley Jevons (1871), Edgeworth (1881), Alfred Marshall (1895), and Vilfredo Pareto (1906). With the refinements introduced by John Hicks (1939) and 
Paul Samuelson (1947), it remains today the standard approach to measuring and predicting consumer welfare. In this era, economists also began to step back from introspective explanations of utility, instead treating it as a black box whose inner workings were not their concern. Irving Fisher (1892) makes the argument:

To fix the idea of utility, the economist should go no further than is serviceable in explaining economic facts. It is not his province to build a theory of psychology.

Whether the necessary antecedent of desire is "pleasure", or whether independently of pleasure it may sometimes be "duty" or "fear" concerns a phenomenon of the second remove from the economic act of choice.

The emphasis on characterizing utility solely in terms of the demand behavior it produced became the centerpiece of neoclassical consumer theory, perfected by Eugen Slutsky (1915), John Hicks (1939) and Paul Samuelson (1947), and in its purest statement forming the theory of revealed preference. This was a great logical achievement, but the demands of the analysis also narrowed and stiffened the way economists thought about preferences. The cardinal, proto-physiological utility of Bentham and Edgeworth was weakened to an ordinal index of preference. The domain of utility moved from activities or processes to the commodity vectors that were the consequence of choice. Self-interest was defined narrowly to include only personally purchased and consumed goods; reciprocity and altruism were ignored. No allowance was made for ambiguities and uncertainties regarding tastes, budgets, the attributes of goods, or the reliability of transactions. The Hicks-Samuelson formulation was fundamentally static, with the consumer making a once-and-for-all utility-maximizing choice of market goods. Utility in this formulation is usually interpreted as the felicity produced by flows of non-durable goods and services from durable goods. However, from the time of Fisher (1930), there were also neoclassical models of intertemporal utility and the dynamics of choice. I will discuss these in more detail in Section VI.5.

The remainder of this section sets notation with an abbreviated restatement of the core of neoclassical demand analysis; introductory treatments are given in standard textbooks; e.g., Varian (1992, Chap. 7, 10), Mas-Colell, Whinston, and Green (1995, Chap. 3E,F,G,I). I will use the theory of duality, with indirect utility functions and expenditure functions linked to demands through Roy's identity and Shephard's identity, respectively. Major features of these dual functions follow from the envelope theorem, developed by Rudolph Auspitz and Richard Lieben (1889), and applied to consumer theory first by Irving Fisher (1892), and later by Harold Hotelling (1935), Rene Roy (1942), Paul Samuelson (1947), Lionel McKenzie (1957), and Hirofumi Uzawa (1971). The full power of dual methods for derivation of demand systems or recovery of utility in econometric applications was not realized until the end of the 1950's, after 
the circulation of the unpublished lecture notes on convexity of Fenchel (1953), and the demonstration by Ron Shephard (1953) of the formal duality of input requirement sets and cost functions. ${ }^{2}$

Let $\mathbf{p}=\left(\mathrm{p}_{1}, \ldots, \mathrm{p}_{\mathrm{n}}\right)$ denote a market good price vector in a positive cone $\mathbf{P} \subseteq \mathbb{R}^{\mathrm{n}}$ and $\mathbf{x}=\left(\mathrm{x}_{1}, \ldots, \mathrm{x}_{\mathrm{n}}\right)$ denote a vector of goods and services in a closed, bounded-below consumption set $\mathbf{X} \subseteq \mathbb{R}^{\mathrm{n}}{ }^{3}$ Let $\mathbf{Z}$ denote a compact metric space of points $\mathbf{z}$ that are placeholders for later analysis of (1) attributes of market or non-market goods, or (2) the consumer's experience, information, social environment, and predetermined choices. For example, $\mathbf{z}$ might characterize a state produced by learning and holdings of durables, or a predetermined location choice that determines the markets that are open to the consumer. ${ }^{4}$ Let $\mathbf{R}$ denote a compact metric space of points $\mathbf{r}$ interpreted as primitive characteristics of the individual (e.g., genetic endowment) that shape tastes. The introduction of $\mathbf{r}$ will facilitate later analysis of unobserved taste heterogeneity.

Suppose a consumer has a continuous utility index $\mathrm{U}(\mathbf{x}, \mathbf{z}, \mathbf{r})$ defined on $\mathbf{X} \times \mathbf{Z} \times \mathbf{R}{ }^{5}$ The fundamental consumer sovereignty assumption of neoclassical theory requires that $\mathbf{r}$ not depend on opportunities or choice. The arguments (z,r) are suppressed in most textbook treatments, but are implicit in the neoclassical theory and can be developed to accommodate some important behavioral phenomena. In the usual theory, the consumer seeks to maximize utility subject to a linear budget constraint $y \geq \mathbf{p} \cdot \mathbf{x}$, where $\mathrm{y}$ is an income level higher than the minimum necessary to make some vector in $\mathbf{X}$ affordable and lower than the

\footnotetext{
${ }^{2}$ I first learned from John Chipman, Leonid Hurwicz, Marc Nerlove, and Hirofumi Uzawa how dual methods could be used to develop demand systems and implement econometric models of production and utility; see Hurwicz and Uzawa (1971) and Fuss and McFadden (1978).

${ }^{3}$ When it is useful to make $\mathbf{X}$ compact in the finite-dimensional case, this can be accomplished by imposing a bound that is not economically restrictive. Most of the results of duality theory continue to hold when prices $\mathbf{p}$ are points in a convex cone $\mathbf{P}$ in a locally convex linear topological space $\mathbf{S}$, and $\mathbf{X}$ is a compact subset of the conjugate space $\mathbf{S}^{*}$ of $\mathbf{S}$. This extension is useful for applications where the consumer is making choices over continuous time, over risky prospects with a continuum of uncertain events, and/or over objects in physical or hedonic space.

${ }^{4}$ In the case of discrete or mutually exclusive alternatives, one can also write $\mathbf{x}=\left(\mathbf{x}_{1}, \ldots, \mathbf{x}_{\mathrm{J}}\right)$, where $\mathbf{x}_{\mathrm{j}}$ is subvector of commodities purchased under discrete choice $\mathrm{j}$. If $\mathbf{x}_{\mathrm{j}}$ includes a dummy variable, its price is interpreted as the direct cost of alternative j. Exclusivity of alternatives is specified through the consumption set $\mathbf{X}$. In this setup, utility maximization may be treated as a joint discrete-continuous decision, or the maximization can be done in stages, typically with discrete choice in the first stage assuming optimal continuous conditional choice in the second stage.

${ }^{5}$ The existence of a continuous utility index is somewhat more than is needed for most duality and demand analysis purposes, but is useful for welfare analysis. Consider the following preference continuity axiom: Suppose consumers with tastes defined by points $\mathbf{r}$ in a compact metric space $\mathbf{R}$ have preferences over objects $(\mathbf{x}, \mathbf{z})$ in $a$ compact metric space $\mathbf{X} \times \mathbf{Z}$, with $\left(\mathbf{x}^{\prime}, \mathbf{z}^{\prime}\right) \mathbf{r}\left(\mathbf{x}^{\prime \prime}, \mathbf{z}^{\prime \prime}\right)$ meaning $\left(\mathbf{x}^{\prime}, \mathbf{z}^{\prime}\right)$ is at least as good as $\left(\mathbf{x}^{\prime \prime}, \mathbf{z}^{\prime \prime}\right)$ for a consumer with tastes $\mathbf{r}$. Suppose $\mathbf{r}$ is a complete, transitive preorder on $\mathbf{X} \times \mathbf{Z}$, and has the continuity property that if a sequence

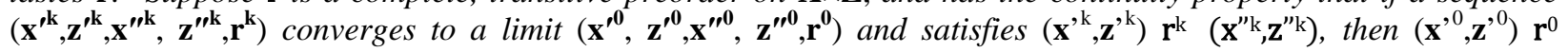
$\left(\mathrm{x}^{\prime \prime}, \mathbf{z}^{\prime \prime}\right)$. McFadden and Train (2000), Lemma 1, establishes that if this axiom holds, then there exists a utility function $U(\mathbf{x}, \mathbf{z}, \mathbf{r})$, continuous in its arguments, that represents $\mathbf{r} \in \mathbf{R}$; see also Bridges (1988).
} 
expenditure needed to attain a bliss point in $\mathbf{X}$. Make the standard assumption that in this range of income, local non-satiation holds, so that all income is spent; e.g., at least one commodity is available in continuous amounts and always desired. In general, we do not require that $\mathbf{X}$ be a convex set, or that preferences be convex; i.e., we do not require that $\mathrm{U}$ be a quasi-concave function of $\mathbf{x}$. Define the Hicksian (compensated) demand function ${ }^{6}$

$$
\mathbf{x}=\mathrm{H}(\mathbf{p}, \mathrm{u}, \mathbf{z}, \mathbf{r}) \equiv \operatorname{argmin}_{\mathrm{x} \in \mathbf{X}}\{\mathbf{p} \cdot \mathbf{x} \mid \mathrm{U}(\mathbf{x}, \mathbf{z}, \mathbf{r}) \geq \mathrm{u}\},
$$

and expenditure function ${ }^{7}$

$$
\mathrm{y}=\mathrm{M}(\mathbf{p}, \mathrm{u}, \mathbf{z}, \mathbf{r}) \equiv \min _{\mathrm{x} \in \mathrm{x}}\{\mathbf{p} \cdot \mathbf{x} \mid \mathrm{U}(\mathbf{x}, \mathbf{z}, \mathbf{r}) \geq \mathrm{u}\}
$$

Income and prices in the expenditure function may be nominal values, or may be deflated to real values. For much of the following development, it is unnecessary to distinguish between nominal and real income and prices, but when the distinction matters, let (p,y) denote nominal values, $\mathrm{A}(\mathbf{p})$ denote a price deflator that is a positive concave conical function of $\mathbf{p}$, and let $(\mathbf{p}, \mathrm{y})=(\mathbf{p} / \mathrm{A}(\mathbf{p}), \mathrm{y} / \mathrm{A}(\mathbf{p}))$ denote real values.

Define the market demand function

$$
\mathbf{x}=\mathrm{D}(\mathbf{p}, \mathrm{y}, \mathbf{z}, \mathbf{r}) \equiv \operatorname{argmax}_{\mathrm{x} \in \mathrm{X}}\{\mathrm{U}(\mathbf{x}, \mathbf{z}, \mathbf{r}) \mid \mathrm{y} \geq \mathbf{p} \cdot \mathbf{x}\}
$$

and the indirect utility function ${ }^{8}$

$$
\mathrm{u}=\mathrm{V}(\mathbf{p}, \mathrm{y}, \mathbf{z}, \mathbf{r}) \equiv \max _{\mathrm{x} \in \mathbf{x}}\{\mathrm{U}(\mathbf{x}, \mathbf{z}, \mathbf{r}) \mid \mathrm{y} \geq \mathbf{p} \cdot \mathbf{x}\}
$$

With local nonsatiation, the expenditure function and indirect utility function satisfy the identities

\footnotetext{
${ }^{6} \mathrm{H}$ is a homogeneous of degree zero, upper hemicontinuous correspondence in $\mathbf{p} \in \mathbf{P}$ for each $(\mathbf{z}, \mathbf{r}) \in \mathbf{Z} \times \mathbf{R}$; see McFadden (1966), Diewert (1974,1982).

${ }^{7} \mathrm{M}$ is strictly increasing in $\mathrm{u}$, and concave and conical (i.e., linear homogeneous) in $\mathbf{p}$, and consequently when $\mathbf{p}$ is finite-dimensional, almost everywhere twice continuously differentiable in $\mathbf{p}$ with symmetric second derivatives. The epigraph $\left\{(\mathbf{p}, \mathrm{y}) \in \mathbb{R}^{\mathrm{n}+1} \mid \mathrm{y} \leq \mathrm{M}(\mathbf{p}, \mathrm{u}, \mathbf{z}, \mathbf{r})\right\}$ is a closed cone, and a vector $\mathbf{x}$ is a support of this cone at $\mathbf{p}$ (i.e., $\mathbf{q} \cdot \mathbf{x} \geq$ $\mathrm{M}(\mathbf{q}, \mathrm{u}, \mathbf{z}, \mathbf{r})$ for all $\mathbf{q} \in \mathbf{P}(\mathrm{u}, \mathbf{z}, \mathbf{r})$, with equality for $\mathbf{q}=\mathbf{p})$, if and only if $\mathbf{x}$ is in the convex hull of $\mathrm{H}(\mathbf{p}, \mathrm{u}, \mathbf{z}, \mathbf{r})$.

${ }^{8} \mathrm{~V}$ is quasi-convex and homogeneous of degree zero in (p,y), and increasing in $\mathrm{y}$, while $\mathrm{D}$ is a homogeneous of degree zero, upper hemicontinuous correspondence in (p,y).
} 
(5)

$$
\begin{aligned}
& \mathrm{y} \equiv \mathrm{M}(\mathbf{p}, \mathrm{V}(\mathbf{p}, \mathrm{y}, \mathbf{z}, \mathbf{r}), \mathbf{z}, \mathbf{r}) \equiv \mathbf{p} \cdot \mathrm{H}(\mathbf{p}, \mathrm{V}(\mathbf{p}, \mathrm{y}, \mathbf{z}, \mathbf{r}), \mathbf{z}, \mathbf{r}) \\
& \mathrm{D}(\mathbf{p}, \mathrm{y}, \mathbf{z}, \mathbf{r}) \equiv \mathrm{H}(\mathbf{p}, \mathrm{V}(\mathbf{p}, \mathrm{y}, \mathbf{z}, \mathbf{r}), \mathbf{z}, \mathbf{r}) \\
& \mathrm{H}(\mathbf{p}, \mathrm{u}, \mathbf{z}, \mathbf{r}) \equiv \mathrm{D}(\mathbf{p}, \mathrm{M}(\mathbf{p}, \mathrm{u}, \mathbf{z}, \mathbf{r}), \mathbf{z}, \mathbf{r}) \\
& \mathrm{V}(\mathbf{p}, \mathrm{y}, \mathbf{z}, \mathbf{r}) \equiv \mathrm{U}(\mathrm{D}(\mathbf{p}, \mathrm{y}, \mathbf{z}, \mathbf{r}), \mathbf{z}, \mathbf{r}) .
\end{aligned}
$$

Shephard's identity establishes that when $\mathrm{M}$ is differentiable in $\mathbf{p}$,

$$
\mathrm{H}(\mathbf{p}, \mathrm{u}, \mathbf{z}, \mathbf{r}) \equiv \nabla_{\mathbf{p}} \mathrm{M}(\mathbf{p}, \mathrm{u}, \mathbf{z}, \mathbf{r}),
$$

while Roy's identity establishes that when $\mathrm{V}$ is differentiable in $\mathbf{p}$ and in $\mathrm{y}$,

$$
\mathrm{D}(\mathbf{p}, \mathrm{y}, \mathbf{z}, \mathbf{r}) \nabla_{\mathrm{y}} \mathrm{V}(\mathbf{p}, \mathrm{y}, \mathbf{z}, \mathbf{r}) \equiv-\nabla_{\mathbf{p}} \mathrm{V}(\mathbf{p}, \mathrm{y}, \mathbf{z}, \mathbf{r})
$$

When $\mathrm{U}(\mathbf{x}, \mathbf{z}, \mathbf{r})$ is quasi-concave and non-decreasing in $\mathbf{x}$, the dual mappings

$$
\mathrm{U}(\mathbf{x}, \mathbf{z}, \mathbf{r})=\min _{\mathrm{p}} \mathrm{V}(\mathbf{p}, \mathbf{p} \cdot \mathbf{x}, \mathbf{z}, \mathbf{r})=\max \{\mathrm{u} \mid \mathbf{p} \cdot \mathbf{x} \geq \mathrm{M}(\mathbf{p}, \mathrm{u}, \mathbf{z}, \mathbf{r}) \text { for } \mathbf{p} \in \mathbf{P}\}
$$

recover the direct utility function; otherwise, they recover the closed quasi-concave free-disposal hull of the direct utility function.

Substituting the direct or indirect utility function into an expenditure function gives a monotone increasing transformation that is again a utility function, now denominated in dollars and termed a money-metric direct or indirect utility function,

$$
\begin{aligned}
& \mathrm{u}=\eta\left(\mathbf{p}^{\prime}, \mathbf{z}^{\prime} ; \mathbf{x}, \mathbf{z}, \mathbf{r}\right) \equiv \mathrm{M}\left(\mathbf{p}^{\prime}, \mathrm{U}(\mathbf{x}, \mathbf{z}, \mathbf{r}), \mathbf{z}^{\prime}, \mathbf{r}\right), \\
& \mathrm{u}=\mu\left(\mathbf{p}^{\prime}, \mathbf{z}^{\prime} ; \mathbf{p}, \mathrm{y}, \mathbf{z}, \mathbf{r}\right) \equiv \mathrm{M}\left(\mathbf{p}^{\prime}, \mathrm{V}(\mathbf{p}, \mathrm{y}, \mathbf{z}, \mathbf{r}), \mathbf{z}^{\prime}, \mathbf{r}\right) .
\end{aligned}
$$

where $\left(\mathbf{p}^{\prime}, \mathbf{z}^{\prime}\right)$ determine a benchmark metric and $(\mathbf{x}, \mathbf{z})$ or $(\mathbf{p}, \mathbf{y}, \mathbf{z})$ determine the utility level. The function $\mu$ behaves like an expenditure function in $\mathbf{p}^{\prime}$ and an indirect utility function in (p,y), and satisfies $\mu(\mathbf{p}, \mathbf{z} ; \mathbf{p}, \mathrm{y}, \mathbf{z}, \mathbf{r}) \equiv \mathrm{y}$; see Hurwicz and Uzawa (1971), Hammond (1994), McFadden (1999).

A concern of neoclassical demand analysis, and a first question for measurement of well-being, is whether preferences or an indirect utility function can be recovered from an individual's observed market 
demand function $\mathrm{D}(\mathbf{p}, \mathrm{y}, \mathbf{z}, \mathbf{r})$, provided it satisfies the necessary conditions implied by utility maximization subject to budgets $\mathbf{y} \geq \mathbf{p} \cdot \mathbf{x}$. With qualifications, affirmative answers have been provided by two different lines of argument. The first, originating in the integrability analysis of Antonelli (1886) and Samuelson (1950), can be characterized as giving sufficient conditions under which Roy's identity (9), treated as a partial differential equation in V, has a solution. Hurwicz and Uzawa (1971) give local and global sufficient conditions for recovery of money-metric indirect utility when market demand functions are single-valued and smooth; a summary of their argument is given by Katzner (1970). The second, originating in the revealed preference analysis of Samuelson (1948), Houthakker (1950), and Richter (1966), gives necessary and sufficient conditions for recovery of a preference order whose maximization yields the observed demand function; Afriat (1967) and Varian (2006) provide constructive methods for recovery of utility under some conditions. Qualifications are required because quite strong smoothness and curvature conditions on utility are needed to assure smoothness properties on market demand, and preferences recovered from upper hemicontinuous demand functions are not necessarily continuous; see Rader (1973), Peleg (1970), Conniffe (2007).

An important caution is that even when consumer behavior is formulated in terms of money-metric utility, and discussed using phrases like "marginal utility of money” and “diminishing marginal utility”, the indices $\mathrm{U}(\mathbf{x}, \mathbf{z}, \mathbf{r})$ and $\mathrm{V}(\mathbf{p}, \mathbf{y}, \mathbf{z}, \mathbf{r})$ that can be recovered from observed demand are purely ordinal. Suppose $\mathbf{z}$ can be partitioned into $\mathbf{z}=\left(\mathbf{z}_{1}, \mathbf{z}_{2}\right)$, where $\mathbf{z}_{1}$ has a direct identifiable effect on market demand and $\mathbf{z}_{2}$ does not influence market demand; i.e., $\mathrm{D}\left(\mathbf{p}, \mathrm{y}, \mathbf{z}_{1}, \mathbf{z}_{2}, \mathbf{r}\right)$ is independent of $\mathbf{z}_{2}$, but if $\mathbf{z}_{1} \neq \mathbf{z}_{1}{ }^{\prime}$, then there exist (p,y,r) such that $\mathrm{D}\left(\mathbf{p}, \mathrm{y}, \mathbf{z}_{1}, \mathbf{z}_{2}, \mathbf{r}\right) \neq \mathrm{D}\left(\mathbf{p}, \mathrm{y}, \mathbf{z}_{1}{ }^{\prime}, \mathbf{z}_{2}, \mathrm{r}\right)$. Let $\mathrm{V}\left(\mathbf{p}, \mathrm{y}, \mathbf{z}_{1}, \mathbf{r}\right)$ denote an "economical” ordinal representation of preferences for market goods that satisfies Roy's identity but does not depend on $\mathbf{z}_{2}$. Suppose there exists a true neurologically-determined hedonic index $\mathrm{V}^{*}\left(\mathbf{p}, \mathrm{y}, \mathbf{z}_{1}, \mathbf{z}_{2}, \mathbf{r}\right)$ that would be ideal for the assessment of consumer welfare, and suppose that it does depend on $\mathbf{z}_{2}$. Because $\mathrm{V}$ and $\mathrm{V}^{*}$ both represent the preferences that determine market demand, they are linked by a transformation $\mathrm{V}^{*}\left(\mathbf{p}, \mathrm{y}, \mathbf{z}_{1}, \mathbf{z}_{2}, \mathbf{r}\right) \equiv \mathrm{f}\left(\mathrm{V}\left(\mathbf{p}, \mathrm{y}, \mathbf{z}_{1}, \mathbf{r}\right), \mathbf{z}_{1}, \mathbf{z}_{2}, \mathbf{r}\right)$, where $f(\cdot, \mathbf{z}, \mathbf{r})$ is a smooth function that is increasing in its first argument. Now, $V$ and $V^{*}$ are equally legitimate utility functions from the standpoint of economic demand analysis. However, even though the variables $\mathbf{z}_{2}$ influence pleasure or pain, they have no influence on market demand behavior, and within neoclassical demand analysis have no identifiable or econometrically recoverable effect on well-being. Section VII discusses contemporary attempts to go outside the neoclassical model to measure such effects by either "making a market" for $\mathbf{z}_{2}$ via incentive-compatible mechanisms for eliciting values, or by utilizing biometric measures of hedonic state. 


\section{First Measurements}

In the days before digital computers, data on consumer behavior was limited and statistical computation was laborious. Consequently, empirical measurement of utility came slowly. One of the first serious attempts was made by Ragnar Frisch (1926, 1932), specializing a framework initially proposed by Irving Fisher (1892, 1918, 1927). Frisch used 31 monthly observations from Paris starting in 1920 on income, and the price and consumption of sugar. Frisch's formulation now seems restrictive and a little awkward, but it was suited to the computational limits of the day and contained the important ideas of separable utility and composite commodities. In modern terminology, Frisch postulated that the demand for sugar could be written as

$$
\mathrm{x}=\mathrm{D}(\mathrm{p}, \mathrm{y}) \equiv \mathrm{f}^{\prime}(\underline{\mathrm{p}}) / \mathrm{g}^{\prime}(\mathrm{y})
$$

where $\mathrm{p}$ was the real price of sugar and $\mathrm{y}$ was real income, with deflation to real values using a price index for a composite of the remaining commodities, $g^{\prime}$ was a decreasing function interpreted as the marginal utility of money, and $\mathrm{f}^{\prime}$ was a decreasing function interpreted as the inverse of the marginal utility of sugar. This demand function has an associated indirect utility function that is additively separable in real income and the real price of sugar, so that the marginal utility of money is independent of the price of sugar,

$$
\mathrm{u}=\mathrm{V}(\mathrm{y}, \underline{\mathrm{p}})=\mathrm{g}(\mathrm{y})-\mathrm{f}(\mathrm{p}) \text {. }
$$

The quasi-convexity requirement for an indirect utility functions is met if $\mathrm{g}$ is convex and $\mathrm{f}$ is concave, but somewhat weaker requirements suffice on a restricted (p,y) domain. ${ }^{9}$

\section{The Stone Age}

Econometric demand analysis flowered in the 1960's, as improved data and digital computers made serious empirical work possible. The real starting point was the contribution of Richard Stone (1954), who estimated expenditure systems linear in income that were derived from Cobb-Douglas demands, translated to allow committed expenditures,

$$
\mathrm{x}_{\mathrm{i}}=\mathrm{c}_{\mathrm{i}}+\theta_{\mathrm{i}}(\mathrm{y}-\mathbf{p} \cdot \mathbf{c}) / \mathrm{p}_{\mathrm{i}}
$$

\footnotetext{
${ }^{9}$ When $\mathrm{f}$ and $\mathrm{g}$ are twice continuously differentiable, a necessary and sufficient condition for quasi-convexity is $\mathrm{f}^{\prime \prime}(\mathrm{p}) / \mathrm{f}^{\prime}(\mathrm{p})^{2} \leq \mathrm{g}^{\prime \prime}(\mathrm{y}) / \mathrm{g}^{\prime}(\mathrm{y})^{2}$. For example, if $\mathrm{g}(\mathrm{y})=\underline{\mathrm{y}}^{1-\alpha} /(1-\alpha)$ and $\mathrm{f}(\mathrm{p})=\mathrm{p}^{1-\beta} /(1-\beta)$, quasi-concavity holds for $(\mathrm{p}, \underline{\mathrm{y}})$ satisfying $\alpha \mathrm{y}^{\alpha-1} \leq \beta \mathrm{p}^{\beta-1}$.
} 
Here, $\mathrm{i}=1, \ldots, \mathrm{n}$ indexes the commodities, $\mathrm{y}$ is income, $\mathbf{p}$ is a vector of commodity prices, $\mathbf{c}=\left(\mathrm{c}_{1}, \ldots, \mathrm{c}_{\mathrm{n}}\right)$ is a vector of committed demands, and $\theta_{1}, \ldots, \theta_{\mathrm{n}}$ are positive parameters that sum to one. The Stone system is a special case $^{10}$ of the polar form of Terance Gorman (1953,1961),

$$
\mathrm{x}_{\mathrm{i}}=\mathrm{C}_{\mathrm{i}}(\mathbf{p}, \mathbf{z}, \mathbf{r})+(\mathrm{y}-\mathrm{C}(\mathbf{p}, \mathbf{z}, \mathbf{r})) \cdot \mathrm{A}_{\mathrm{i}}(\mathbf{p}, \mathbf{z}, \mathbf{r}) / \mathrm{A}(\mathbf{p}, \mathbf{z}, \mathbf{r}),
$$

where $\mathrm{C}$ and $\mathrm{A}$ are concave, non-decreasing, conical functions of prices that may depend on experience and tastes through the arguments (z,r), derived from an indirect utility function

$$
\mathrm{u}=(\mathrm{y}-\mathrm{C}(\mathbf{p}, \mathbf{z}, \mathbf{r})) / \mathrm{A}(\mathbf{p}, \mathbf{z}, \mathbf{r})
$$

and $C_{i}$ and $A_{i}$ denote derivatives with respect to $\mathrm{p}_{i}$. The Gorman polar form can be generalized to allow more flexible Engle curves by introducing a monotone transformation of deflated income,

$$
\mathrm{u}=\mathrm{g}(\mathrm{y} / \mathrm{A}(\mathbf{p}, \mathbf{z}, \mathbf{r}))-\mathrm{C}(\mathbf{p}, \mathbf{z}, \mathbf{r}) / \mathrm{A}(\mathbf{p}, \mathbf{z}, \mathbf{r})
$$

with quasi-convexity of the indirect utility function restricting the curvature of g and/or the domain of (p,y). The corresponding demand function is

$$
\mathrm{x}_{\mathrm{i}}=\mathrm{C}_{\mathrm{i}}(\mathbf{p}, \mathbf{z}, \mathbf{r}) / \mathrm{g}^{\prime}(\mathrm{y} / \mathrm{A}(\mathbf{p}, \mathbf{z}, \mathbf{r}))+\left(\mathrm{y}-\mathrm{C}(\mathbf{p}, \mathbf{z}, \mathbf{r}) / \mathrm{g}^{\prime}(\mathrm{y} / \mathrm{A}(\mathbf{p}, \mathbf{z}, \mathbf{r}))\right) \mathrm{A}_{\mathrm{i}}(\mathbf{p}, \mathbf{z}, \mathbf{r}) / \mathrm{A}(\mathbf{p}, \mathbf{z}, \mathbf{r})
$$

Frisch's original demand function for sugar is of this generalized Gorman polar form, with sugar excluded from the price index $A(\mathbf{p})$.

In the 1960' and 1970's, a variety of econometric demand systems were proposed, many derived from specifications of expenditure or indirect utility functions. Important early contributions were the direct and indirect addilog systems of Houthakker (1960), and the CES form of Arrow-Chenery-Minhas-Solow (1961). A number of econometric demand systems were developed at Berkeley by students working with me and my colleagues Dale Jorgenson and Robert Hall. In 1963, Erwin Diewert proposed a Generalized Leontief cost function that was quadratic in square roots of prices; see Diewert (1971), Blackorby and Diewert (1979). I pointed out that this system could be interpreted as a second-order Taylor's expansion

\footnotetext{
${ }^{10}$ The polar form reduces to the Stone form when $\mathrm{C}(\mathbf{p}, \mathbf{z}, \mathbf{r})=\mathrm{p} \cdot \mathbf{c}$ and $\mathrm{A}(\mathbf{p}, \mathbf{z}, \mathbf{r})=\left(p_{1}\right)^{\theta_{1}} \ldots \cdot\left(p_{n}\right)^{\theta_{n}}$.
} 
of any smooth cost function, so that it had the nice property that at the approximation point it could reproduce all the own and cross-price elasticities of the original. We named this the flexible functional form property, and it became one of the criteria guiding subsequent developments. Dale Jorgenson and Larry Lau devised the translog system, another flexible functional form that generalized the Houthakker indirect addilog system; see Christensen-Jorgenson-Lau (1975). Another major contribution to the specification of demand systems, influenced by both the Berkeley tradition and by Terance Gorman, was the Almost Ideal Demand System proposed by Angus Deaton and John Muellbauer (1980ab), with the indirect utility function

$$
\mathrm{u}=\left[\ln \mathrm{y}-\alpha_{0}-\sum_{k=1}^{n} \alpha_{k} \ln p_{k}-1 / 2 \sum_{k=1}^{n} \sum_{j=1}^{n} \gamma_{\mathrm{kj}} \ln p_{k} \ln p_{j}\right] / \beta_{0} \prod_{k=1}^{n}\left(p_{k}\right)^{\beta_{k}}
$$

and demand functions whose expenditure shares are linear in logs of income and prices. This is a Gorman generalized polar form with translog committed expenditures and a Cobb-Douglas price index. Zero degree homogeneity of (17) in income and prices requires the parameter restrictions $\gamma_{k j}=\gamma_{j k}$, $\sum_{k=1}^{n} \alpha_{k}=1, \sum_{k=1}^{n} \beta_{k}=1$, and $\sum_{k=1}^{n} \gamma_{k j}=0$, and quasi-convexity restricts the (p,y) domain. In general, the parameters in (17) depend on $\mathbf{r}$ and can be functions of $\mathbf{z}$.

While the demand systems (12)-(17) were derived from the theory of the individual consumer, they were typically applied to observations on cross-sections of individuals, or to market aggregates, by assuming a representative consumer. Except under special circumstances (see for example John Chipman and James Moore, 1980, 1990), this presumed homogeneous preferences, or in the later work of Dale Jorgenson, Larry Lau, and Tom Stoker $(1980,1997)$ and Arthur Lewbel (1992), preference heterogeneity parameterized as a function of observables.

The utility-consistent demand systems mentioned above generally worked well to explain demand at the market level despite the representative consumer restriction. Lester Taylor (2005) estimates neoclassical demand systems using U.S. Consumer Expenditure Survey quarterly expenditure data and ACCRA Cost of Living indices across urban areas in six expenditure categories. Table 1 gives price and expenditure elasticities for an Almost Ideal Demand System fitted to these data. An example of the use these results is calculation of excise tax structures that maximize well-being subject to budget and distributional constraints. Taylor points out that there are substantive aggregation, quality, and taste heterogeneity issues in the use of such data, but his results are generally consistent with other studies. He finds that Stone, indirect addilog, and direct addilog systems give qualitatively similar results.

\section{TABLE 1 ABOUT HERE}




\section{Consumer Well-Being}

How does a change in a consumer's economic environment from $\left(\mathbf{p}^{\prime}, \mathrm{y}^{\prime}, \mathbf{z}^{\prime}\right)$ to $\left(\mathbf{p}^{\prime \prime}, \mathrm{y}^{\prime \prime}, \mathbf{z}^{\prime \prime}\right)$ affect her indirect utility, the neoclassical measure of well-being? The concept of consumer surplus from Dupuit, Marshall, and Hicks can be interpreted as a money metric for changes in indirect utility, an adjustment to income that equates indirect utilities before and after a change in the economic environment. The Compensating Variation or Willingness-to-Pay (WTP) for this change is the net reduction in final income that makes the consumer indifferent to the change, $V\left(\mathbf{p}^{\prime \prime}, \mathrm{y}^{\prime \prime}-\mathrm{WTP}, \mathbf{z}^{\prime \prime}, \mathbf{r}\right)=\mathrm{V}\left(\mathbf{p}^{\prime}, \mathrm{y}^{\prime}, \mathbf{z}^{\prime}, \mathbf{r}\right)$. Substituting these values into the expenditure function gives the money-metric equality $\mu\left(\mathbf{p}^{\prime \prime}, \mathbf{z}^{\prime \prime} ; \mathbf{p}^{\prime}, \mathrm{y}^{\prime}, \mathbf{z}^{\prime}, \mathbf{r}\right)=\mu\left(\mathbf{p}^{\prime \prime}, \mathbf{z}^{\prime \prime} ; \mathbf{p}^{\prime \prime}, \mathrm{y}^{\prime \prime}\right.$ WTP, $\left.\mathbf{z}^{\prime \prime}, \mathbf{r}\right) \equiv \mathrm{y}^{\prime \prime}-\mathrm{WTP}$, or

$$
\begin{aligned}
\text { WTP } & =\mu\left(\mathbf{p}^{\prime \prime}, \mathbf{z}^{\prime \prime} ; \mathbf{p}^{\prime \prime}, \mathrm{y}^{\prime \prime}, \mathbf{z}^{\prime \prime}, \mathbf{r}\right)-\mu\left(\mathbf{p}^{\prime \prime}, \mathbf{z}^{\prime \prime} ; \mathbf{p}^{\prime}, \mathrm{y}^{\prime}, \mathbf{z}^{\prime}, \mathbf{r}\right) \equiv \mathrm{y}^{\prime \prime}-\mu\left(\mathbf{p}^{\prime \prime}, \mathbf{z}^{\prime \prime} ; \mathbf{p}^{\prime}, \mathrm{y}^{\prime}, \mathbf{z}^{\prime}, \mathbf{r}\right) \\
& \equiv\left\{\mathrm{y}^{\prime \prime}-\mathrm{y}^{\prime}\right\}-\left\{\mu\left(\mathbf{p}^{\prime}, \mathbf{z}^{\prime \prime} ; \mathbf{p}^{\prime}, \mathrm{y}^{\prime}, \mathbf{z}^{\prime}, \mathbf{r}\right)-\mu\left(\mathbf{p}^{\prime}, \mathbf{z}^{\prime} ; \mathbf{p}^{\prime}, \mathrm{y}^{\prime}, \mathbf{z}^{\prime}, \mathbf{r}\right)\right\}-\left\{\mu\left(\mathbf{p}^{\prime \prime}, \mathbf{z}^{\prime \prime} ; \mathbf{p}^{\prime}, \mathrm{y}^{\prime}, \mathbf{z}^{\prime}, \mathbf{r}\right)-\mu\left(\mathbf{p}^{\prime}, \mathbf{z}^{\prime \prime} ; \mathbf{p}^{\prime}, \mathrm{y}^{\prime}, \mathbf{z}^{\prime}, \mathbf{r}\right)\right\}
\end{aligned}
$$

The last identity decomposes WTP into the observed net increase in money income, less the net increase in income necessary at initial prices and utility level to offset the change in non-market attributes, less the net increase in income necessary to offset the change in prices at the final non-market attributes and initial utility level. The last bracketed term in (18) can be written

$$
\mu\left(\mathbf{p}^{\prime \prime}, \mathbf{z}^{\prime \prime} ; \mathbf{p}^{\prime}, \mathrm{y}^{\prime}, \mathbf{z}^{\prime}, \mathbf{r}\right)-\mu\left(\mathbf{p}^{\prime}, \mathbf{z}^{\prime \prime} ; \mathbf{p}^{\prime}, \mathrm{y}^{\prime}, \mathbf{z}^{\prime}, \mathbf{r}\right)=\oint_{p^{\prime}}^{p \prime \prime} H\left(\mathbf{p}, \mathrm{u}^{\prime}, \mathbf{z}^{\prime \prime}, \mathbf{r}\right) \cdot \mathrm{d} \mathbf{p}
$$

the Hicksian net consumer surplus from the price change from $\mathbf{p}^{\prime}$ to $\mathbf{p}^{\prime \prime}$, where $\mathrm{u}^{\prime}=\mathrm{V}\left(\mathbf{p}^{\prime}, \mathrm{y}^{\prime}, \mathbf{z}^{\prime}, \mathbf{r}\right)$ is the initial utility level. This integral is independent of path and can be taken over any rectifiable path from $\mathbf{p}^{\prime}$ to $\mathbf{p}^{\prime \prime}$. Thus, when $\mathbf{z}^{\prime \prime}=\mathbf{z}^{\prime}$ and $\mathrm{y}^{\prime \prime}=\mathrm{y}^{\prime}$, so that only price changes, WTP equals the Hicksian consumer surplus.

The Equivalent Variation or Willingness-to-Accept (WTA) the change is the net addition to initial income that makes the consumer indifferent to the change, $V\left(\mathbf{p}^{\prime \prime}, \mathrm{y}^{\prime \prime}, \mathbf{z}^{\prime \prime}, \mathbf{r}\right)=\mathrm{V}\left(\mathbf{p}^{\prime}, \mathrm{y}^{\prime}+\mathrm{WTA}, \mathbf{z}^{\prime}, \mathbf{r}\right)$, or

$$
\begin{aligned}
& \text { WTA }=\mu\left(\mathbf{p}^{\prime}, \mathbf{z}^{\prime} ; \mathbf{p}^{\prime \prime}, \mathrm{y}^{\prime \prime}, \mathbf{z}^{\prime \prime}, \mathbf{r}\right)-\mu\left(\mathbf{p}^{\prime}, \mathbf{z}^{\prime} ; \mathbf{p}^{\prime}, \mathrm{y}^{\prime}, \mathbf{z}^{\prime}, \mathbf{r}\right) \equiv \mu\left(\mathbf{p}^{\prime}, \mathbf{z}^{\prime} ; \mathbf{p}^{\prime \prime}, \mathrm{y}^{\prime \prime}, \mathbf{z}^{\prime \prime}, \mathbf{r}\right)-\mathrm{y}^{\prime} \\
& \quad \equiv\left\{\mathrm{y}^{\prime \prime}-\mathrm{y}^{\prime}\right\}-\left\{\mu\left(\mathbf{p}^{\prime \prime}, \mathbf{z}^{\prime \prime} ; \mathbf{p}^{\prime \prime}, \mathrm{y}^{\prime \prime}, \mathbf{z}^{\prime \prime}, \mathbf{r}\right)-\mu\left(\mathbf{p}^{\prime \prime}, \mathbf{z}^{\prime} ; \mathbf{p}^{\prime \prime}, \mathrm{y}^{\prime \prime}, \mathbf{z}^{\prime \prime}, \mathbf{r}\right)\right\}-\left\{\mu\left(\mathbf{p}^{\prime \prime}, \mathbf{z}^{\prime} ; \mathbf{p}^{\prime \prime}, \mathrm{y}^{\prime \prime}, \mathbf{z}^{\prime}, \mathbf{r}\right)-\mu\left(\mathbf{p}^{\prime}, \mathbf{z}^{\prime} ; \mathbf{p}^{\prime \prime}, \mathrm{y}^{\prime \prime}, \mathbf{z}^{\prime \prime}, \mathbf{r}\right)\right\}
\end{aligned}
$$

Again, the final decomposition is the observed net increase in money income, less the net increase in income necessary at final prices and utility level to offset the change in non-market attributes, less the net 
increase in income necessary to offset the change in prices at the initial non-market attributes and final utility level, with the last term expressible as a Hicksian consumer surplus integral similar to (19), but with Hicksian demand evaluated at the final utility level $\mathbf{u}^{\prime \prime}=\mathrm{V}\left(\mathbf{p}^{\prime \prime}, \mathrm{y}^{\prime \prime}, \mathbf{z}^{\prime \prime}, \mathbf{r}\right)$.

Putting income and prices in real terms and using the first identity in (5), the definition (9), and the theorem of the mean, WTP and WTA can be written

$$
\begin{aligned}
\underline{\mathrm{WTP}} & =\left[\mathrm{V}\left(\mathbf{p}^{\prime \prime}, \mathrm{y}^{\prime \prime}, \mathbf{z}^{\prime \prime}, \mathbf{r}\right)-\mathrm{V}\left(\mathbf{p}^{\prime}, \mathrm{y}^{\prime}, \mathbf{z}^{\prime}, \mathbf{r}\right)\right] / \nabla_{\mathrm{y}} \mathrm{V}\left(\mathbf{p}^{\prime \prime}, \mathrm{y}^{\mathrm{a}}, \mathbf{z}^{\prime \prime}, \mathbf{r}\right) \\
& \approx \underline{\mathrm{MWTP}} \equiv\left[\mathrm{V}\left(\underline{\mathbf{p}}^{\prime \prime}, \mathrm{y}^{\prime \prime}, \mathbf{z}^{\prime \prime}, \mathbf{r}\right)-\mathrm{V}\left(\underline{\mathbf{p}}^{\prime}, \mathrm{y}^{\prime}, \mathbf{z}^{\prime}, \mathbf{r}\right)\right] / \nabla_{\mathrm{y}} \mathrm{V}\left(\underline{\mathbf{p}}^{\prime \prime}, \mathrm{y}^{\prime \prime}, \mathbf{z}^{\prime \prime}, \mathbf{r}\right), \\
\underline{\mathrm{WTA}} & =\left[\mathrm{V}\left(\mathbf{p}^{\prime \prime}, \mathrm{y}^{\prime \prime}, \mathbf{z}^{\prime \prime}, \mathbf{r}\right)-\mathrm{V}\left(\underline{\mathbf{p}}^{\prime}, \mathrm{y}^{\prime}, \mathbf{z}^{\prime}, \mathbf{r}\right)\right] / \nabla_{\mathrm{y}} \mathrm{V}\left(\underline{\mathbf{p}}^{\prime}, \mathrm{y}^{\mathrm{b}}, \mathbf{z}^{\prime}, \mathbf{r}\right) \\
& \approx \underline{\mathrm{MWTA}} \equiv\left[\mathrm{V}\left(\mathbf{p}^{\prime \prime}, \mathrm{y}^{\prime \prime}, \mathbf{z}^{\prime \prime}, \mathbf{r}\right)-\mathrm{V}\left(\underline{\mathbf{p}}^{\prime}, \mathrm{y}^{\prime}, \mathbf{z}^{\prime}, \mathbf{r}\right)\right] / \nabla_{\mathrm{y}} \mathrm{V}\left(\mathbf{p}^{\prime}, \mathrm{y}^{\prime}, \mathbf{z}^{\prime}, \mathbf{r}\right),
\end{aligned}
$$

where $\mathrm{y}^{\mathrm{a}}$ and $\mathrm{y}^{\mathrm{b}}$ are points in the line segment between $\mathrm{y}^{\prime}$ and $\mathrm{y}^{\prime \prime}$, marginal willingness-to-pay (MWTP) approximates WTP when $\mathrm{y}^{\prime}$ and $\mathrm{y}^{\prime \prime}$ are close, and marginal willingness to accept (WWA) approximates $\underline{\text { WTA }}$ when $\mathrm{y}^{\prime}$ and $\mathrm{y}^{\prime \prime}$ are close. An implication of (21) is that WTP, MWTP, WTA, and MWTA all have the same sign, and can be interpreted as alternative scalings of the indirect utility difference $\mathrm{V}\left(\mathbf{p}^{\prime \prime}, \mathrm{y}^{\prime \prime}, \mathbf{z}^{\prime \prime}, \mathbf{r}\right)$ $\mathrm{V}\left(\mathbf{p}^{\prime}, \mathrm{y}^{\prime}, \mathbf{z}^{\prime}, \mathbf{r}\right)$. If before and after prices are scaled so that $\underline{\mathrm{y}}^{\prime}=\underline{\mathrm{y}}^{\prime \prime}$, then $\underline{\mathrm{WTP}}$ and $\underline{\text { MWTP }}$ coincide, as do $\underline{\text { WTA }}$ and MWTA. This result also holds if the marginal utility of income is independent of $\mathrm{y}$, a case that corresponds, at least locally, to an indirect utility function $V(\mathbf{p}, \mathbf{y}, \mathbf{z}, \mathbf{r})=\mathrm{V}_{1}(\mathbf{p}, \mathbf{z}, \mathbf{r}) \cdot \mathbf{y}+\mathrm{V}_{2}(\mathbf{p}, \mathbf{z}, \mathbf{r})$ that is linear in real income. If the marginal utility of income is independent not only of $\mathbf{y}$, but also of $\mathbf{p}$ and $\mathbf{z}$, then $\underline{\mathrm{WTP}}$ and WTA coincide, and the indirect utility function reduces to $\mathrm{V}(\underline{\mathbf{p}}, \mathrm{y}, \mathbf{z}, \mathbf{r})=\mathrm{V}_{1}(\mathbf{r}) \cdot \mathrm{y}+\mathrm{V}_{2}(\mathbf{p}, \mathbf{z}, \mathbf{r})$. The Gorman polar form has this structure, and allows easy welfare calculations, with WTP and WTA differing only by a scale factor, WTP/A $\left(\mathbf{p}^{\prime \prime}, \mathbf{z}^{\prime \prime}, \mathbf{r}\right)=\mathrm{WTA} / \mathrm{A}\left(\mathbf{p}^{\prime}, \mathbf{z}^{\prime}, \mathbf{r}\right)=\left[\mathrm{y}^{\prime \prime}-\underline{\mathrm{y}}^{\prime}-\mathrm{C}\left(\mathbf{p}^{\prime \prime}, \mathbf{z}^{\prime \prime}, \mathbf{r}\right)+\mathrm{C}\left(\mathbf{p}^{\prime}, \mathbf{z}^{\prime}, \mathbf{r}\right)\right]$.

Neoclassical measurement of well-being starts from the assumption that one can identify and recover the market demand functions $\mathbf{x}=\mathrm{D}(\mathbf{p}, \mathrm{y}, \mathbf{z}, \mathbf{r})$ of individuals, and infer from these the features of money-metric utility necessary to do the consumer surplus calculation. Examine this question in the formula (18) for the WTP of an individual consumer. The first term in the final decomposition of (18) is just an observed income difference. The last term, the Hicksian consumer surplus, can be recovered or bounded by first recovering the demand function using observations on choice at different prices and incomes from the same preferences, and it is well known that with sufficient variation in budgets, one can bound or recover exactly the Hicksian net consumer surplus associated with price variations, the final term in the decomposition of (18); see Henrick Houthakker (1950), Robert Willig (1976), Hal Varian (1982). 
This leaves the middle term in (18) to be identified. McFadden (2008) argues that this requires either that choice be observed in which the environment $\mathbf{z}$ is determinative at an active margin, for example because $\mathbf{z}$ and $\mathbf{p}$ influence utility in a known interaction, or because discrete choices are made that select the environment; or that some non-market information on well-being be collected and used. McFadden (1986, 1994, 1999, 2004) gives detailed discussions of identifying or bounding WTP and WTA using both revealed and hypothetical choice data. In practice, the identification of demand for individual consumers is a challenging task. The market rarely provides natural experiments in which the same individual reveals demand in repeated choice situations that span a full domain (p,y) of prices and incomes, and a consumer's choice history modifies the experience vector $\mathbf{z}$ systematically, so that it will often be difficult to identify the separate effects of (p,y) and $\mathbf{z}$. Only components of $\mathbf{z}$ that have active margins, in the sense that changing $\mathbf{z}$ changes market behavior, have neoclassically identifiable effects. Tacit in most applications of neoclassical welfare analysis is an assumption that market good prices and non-market attributes interact in such a way that changes in $\mathbf{z}$ can be translated into changes in effective market prices, and rolled into the consumer surplus calculation. For example, suppose direct utility is $U\left(\mathbf{x}^{*}, \mathbf{r}\right)$, where $x^{*}{ }_{j}=x_{j} \cdot f_{j}(\mathbf{z})$ is the "quality-corrected" amount of good $\mathrm{j}$, with an associated indirect utility function $\mathrm{V}\left(\mathbf{p}^{*}, \mathrm{y}, \mathbf{r}\right)$ of income and effective prices $\mathrm{p}^{*}{ }_{\mathrm{j}}=\mathrm{p}_{\mathrm{j}} / \mathrm{f}_{\mathrm{j}}(\mathbf{z})$. Then $\mathbf{z}$ influences indirect utility only through effective prices, and the contribution to WTP from changes in $\mathbf{p}$ and $\mathbf{z}$ is given by a consumer surplus integral of the form (19) between initial and final effective prices, with a Hicksian demand integrand that also depends on $\mathbf{z}$ only through the effective prices.

The expressions (18)-(21) represent the full neoclassical elaboration of Dupuit's characterization of changes in well-being for consumers facing linear budget constraints, incorporating Hick's refinement of compensating for the effect of income on marginal utility. However, as noted at the end of Section II, the effect on well-being of changes in non-market attributes $\mathbf{z}$ may not be identified from observable neoclassical demand behavior.

\section{Expansions}

As microdata on individuals and computational capacity have expanded over the last half-century, neoclassical econometric demand systems predicated on linear budget sets and representative consumers have proven uncomfortably restrictive. These systems could not deal easily with preference heterogeneity, acquired tastes, shifting hedonic attributes of commodities, non-linear budget sets, time, space, or uncertainty, and the frequent cases of zero and lumpy purchases. It was necessary to expand the domain of the theory. This was done initially by retaining the central elements of standard neoclassical consumer theory, and bringing forward some of the broader components of utilitarianism in a way that was 
consistent with the neoclassical core, as illustrated in Figure 2. This meant preserving the tenets of consumer sovereignty and preference maximization, but admitting the influence of (observed and unobserved) experience and memory on perceptions and on current preferences, leading to heterogeneity across consumers. These extensions also allowed household production, non-linear budget constraints, and utility maximization with strategic optimization and recalculation as events unfold. The following subsections describe each of these extensions.

\section{FIGURE 2 ABOUT HERE}

VI.1. Preference Heterogeneity. The extension of neoclassical consumer theory to handle both tastes acquired as the result of observable experience and history and unobserved preference heterogeneity is a reaffirmation of circumstances allowed in the neoclassical model, but pushed aside to facilitate exposition and econometric estimation. In the summary given in the previous sections, I wrote utility $\mathrm{U}(\mathbf{x}, \mathbf{z}, \mathbf{r})$ as a function of observed experience $\mathbf{z}$ and unobserved tastes $\mathbf{r}$, and these effects carried into the demand functions as arguments. A family of utility functions $\mathrm{U}(\cdot, ;, \mathbf{r})$ on $\mathbf{R}$ is termed a preference field, and a distribution on $\mathbf{r}$ determines a distribution of demands given $\mathbf{z}$ and market variables (p,y). ${ }^{11}$ Observed demand distributions then restrict or identify the underlying distributions of unobserved tastes. The primary problems in application are practical; how to measure and fold into the utility function all the varied experiences of consumers, and how to embed within the system and characterize the distribution of unobservable components of tastes. My original treatment of discrete choice as a result of random utility maximization (McFadden, 1974; Domencich and McFadden, 1974) illustrates a parametric solution. Modern developments allow both flexible parametric and nonparametric estimation; see, for example, Horowitz and Savin (2001), Horowitz (1992), Huang and Nychka (2000), Ichimura and Lee (1991), Ichimura and Thompson (1998), Matzkin (1992, 1993), Pagan and Ullah (1999), Signorini and Jones (2004), Blundell et al $(2008,2012)$.

\footnotetext{
${ }^{11}$ Realized distributions of demands are obtained with incomes drawn from a distribution that may be conditioned on $(\mathbf{z}, \mathbf{r})$ through ecological correlation and the influence of tastes on work history. In some applications, $\mathbf{z}$ is exogenous to the consumer, and thus independent of income and tastes. For example, a product attribute such as durability may be uniform for all consumers. In other applications, the $\mathbf{z}$ are an endogenous part of consumer choice, such as congestion levels, or residential location in response to air pollution levels, and thus have a distribution that is dependent upon income and tastes. A satisfactory model for WTP in the presence of endogenously determined environmental attributes requires specification of the structure of supply as well as demand, and determination of an equilibrium allocation in both market goods and the non-market environments. WTP is then defined on an equilibrium trajectory from old to new environmental, income, and market management policies. In the terminology of the statistical and econometric literature on treatment effects, the final state in the welfare comparison is a fully consistent equilibrium counterfactual.
} 
There are advantages to shifting the focus of consumer theory from individual preferences to distributions of preferences. Both market demand and social welfare are functions of these distributions, and do not require detailed preference information at the individual level. This can substantially reduce the requirements for information and experimental variation relative to those needed to identify individual utilities. Random and fixed effects panel data models in econometrics are an instructive analogy - random effects models require much less data for identification, but also require independence assumptions that are not needed in fixed-effects estimation. However, preference heterogeneity raises conceptual issues. Is unobserved taste variation a permanent individual effect, or is there a component that varies with time or choice opportunity? The neoclassical presumption is that tastes within an individual are fixed. This is the setup of revealed preference theory, which envisions a sequence of budgets offered to an individual whose tastes are uninfluenced by the experience of previous offers, or by whims. Alternately, individual tastes may have an unobserved time-varying component. This is in itself not inconsistent with classical utilitarianism, which left room for utility to reflect "a moment's fancy". However, the presence of taste variations or hysterisis across a revealed preference sequence undermines the main revealed preference result that the convex hull of preferences can be recovered from observed demands. If instead preferences are treated as stochastic, interesting possibilities open for models with both intra-individual and cross-individual heterogeneity. Employing the theory of stochastic revealed preference (Marschak, 1960, Block and Marschak, 1960, Luce and Supes, 1965, McFadden and Richter, 1990, McFadden, 2005, Fosgerau and McFadden, 2012), and panel data on demand, one could ask for conditions under which the distributions of the unobserved taste heterogeneity can be nonparametrically identified. Is it possible to untangle state-dependence and unobserved individual effects in consumer panels, the Heckman initial-values problem? Is it possible to separate heterogeneity in perceptions from heterogeneity in tastes when choice alternatives are risky or ambiguous? Is it possible to identify the distribution of preferences from market-level demand observations? ${ }^{14}$

VI.2. Nonlinear Budget Sets. The neoclassical focus on linear budgets and convex preferences neglected a range of consumer behavior that is apparent at the level of the individual, the lumpiness and mutual exclusivity of many consumer choices such as school, job, and brand of automobile. It also neglected the important economic area of nonlinear pricing, arising from two-part and nonlinear tariffs, and progressive taxes. Extending econometric consumer theory to handle these applications required attention

\footnotetext{
${ }^{14}$ The answer to this question depends on what one knows about the resources available to individuals; see Debreu (1974), McFadden-Mas Colell-Mantel-Richter (1974), Matzkin (2005).
} 
to the role of taste heterogeneity, and to the characterization of budgets. The duality methods that are so useful in linear budget problems are hampered here, but still valuable, for example in Hausman (1985) and Dubin and McFadden (1984). One important observation for measurement of consumer well-being is that non-linear budget sets can be helpful in identifying neoclassical preferences. For example, preferences are recovered directly when budgets are restricted to binary comparisons.

A useful tool for analyzing nonlinear budget sets within the framework of the neoclassical utility model, introduced by Matzkin and McFadden (2011) and developed by Fosgerau and McFadden (2012), considers a preference field formed by taking a base money-metric direct utility function $\eta\left(\mathbf{p}^{\prime}, \mathbf{z}^{\prime} ; \mathbf{x}, \mathbf{z}, \mathbf{r}\right)$ as in (9) that is continuous in its arguments and embedding it in a family formed by additive linear perturbations $\mathbf{q}$ of marginal utility, $\eta\left(\mathbf{p}^{\prime}, \mathbf{z}^{\prime} ; \mathbf{x}, \mathbf{z}, \mathbf{r}\right)+\mathbf{q} \cdot \mathbf{x}$. The perturbations introduced in this analysis can be treated as a technical device and set to a fixed value at the end, but the full power of the approach is attained when these are true unobserved preference perturbations $\mathbf{q}$ that have an absolutely continuous distribution in the population. Fix the benchmark $\left(\mathbf{p}^{\prime}, \mathbf{z}^{\prime}\right)$ and define the money-metric indirect utility function $\mathrm{V}(\mathbf{B}, \mathbf{z}, \mathbf{r}, \mathbf{q})=$ $\max _{\mathbf{x} \in \mathrm{B}}\left\{\eta\left(\mathbf{p}^{\prime}, \mathbf{z}^{\prime} ; \mathbf{x}, \mathbf{z}, \mathbf{r}\right)+\mathbf{q} \cdot \mathbf{x}\right\}$ and demand function $\mathrm{D}(\mathbf{B}, \mathbf{z}, \mathbf{r}, \mathbf{q})=\operatorname{argmax}_{\mathbf{x} \in \mathrm{B}}\left\{\eta\left(\mathbf{p}^{\prime}, \mathbf{z}^{\prime} ; \mathbf{x}, \mathbf{z}, \mathbf{r}\right)+\mathbf{q} \cdot \mathbf{x}\right\}$ for any non-empty compact budget set $\mathbf{B}$ that intersects the consumption set $\mathbf{X}$. Then, $\mathrm{V}$ is a convex function of $\mathbf{q}$, the convex hull of $\mathrm{D}(\mathbf{B}, \mathbf{z}, \mathbf{r}, \mathbf{q})$ equals the subdifferential of $\mathrm{V}$ with respect to $\mathbf{q}$, and for almost all $\mathbf{q}$, $\mathrm{D}(\mathbf{B}, \mathbf{z}, \mathbf{r}, \mathbf{q})$ is a singleton. Thus, the perturbation vector $\mathbf{q}$ plays the same role for general budget sets that prices play in a standard expenditure function for linear budget sets. Fosgerau and McFadden give necessary and sufficient conditions for $\mathrm{V}$ to be a money metric indirect utility function for a family of nonlinear budget sets. These conditions can be used in applications to generate generalizations of neoclassical expenditure systems and construct WTP measures for nonlinear budget sets.

VI.3. Hedonic Goods and Household Production. Economists moved in the 1970's from treating commodities as objects with fixed attributes to hedonic models in which consumers care about generic attributes that can be met through various quantities and combinations of market goods. The simplest hedonic model, dating to Andrew Court (1939), Kevin Lancaster (1966), and John Muth (1998), allowed the hedonic content of a unit of a market good to vary with the design of its manufacturer, and assumed in implementation that these dimensions of content could be measured. Extending this approach, consumers may be thought of as obtaining various observed and unobserved hedonic quantities through a combination of the direct hedonic content of market goods and household production of hedonic content. For example, an automobile contains as direct hedonic content "horsepower" and "cargo capacity", and requires the household production activities of driving and parking to facilitate foraging for food and satisfying hunger. 
Household production is a feature of economic life whose presence influences consumer's economic behavior, and enriches the interpretation but complicates the measurement of utility, and also offers additional measurement opportunities. Economists invoke household production ideas to explain time allocation, and facilitating activities like travel. Nevertheless, household production is given little attention in economics textbooks. I think one reason for this is that unless one has observations on household production activities or hedonic products of the household production process, one cannot distinguish household technology from tastes. To illustrate, let $\mathbf{w}=\left(\mathrm{w}_{1}, \ldots, \mathrm{w}_{\mathrm{K}}\right)$ denote hedonic quantities, $\mathbf{z}$ denote the consumer's environment, $\mathbf{x}=\left(\mathrm{x}_{1}, \ldots, \mathrm{x}_{\mathrm{N}}\right)$ denote market goods, $\mathrm{y}$ denote income, and $\mathbf{p}=$ $\left(\mathrm{p}_{1}, \ldots, \mathrm{p}_{\mathrm{N}}\right)$ denote market good prices. Let $\mathrm{F}(\mathbf{w}, \mathbf{x}, \mathbf{z}) \leq 0$ denote the household technology, and $\mathrm{U}(\mathbf{w}, \mathbf{z}, \mathbf{r})$ denote the direct utility function. Then, the consumer's indirect utility satisfies

$$
\mathrm{V}(\mathrm{y}, \mathbf{p}, \mathbf{z}, \mathbf{r})=\max _{\mathrm{z}, \mathrm{x}} \mathrm{U}(\mathbf{w}, \mathbf{r}) \quad \text { s.t. } \quad \mathrm{F}(\mathbf{w}, \mathbf{x}, \mathbf{z}) \leq 0, \mathbf{p} \cdot \mathbf{x} \leq \mathrm{y}
$$

Given this indirect utility function, apply the duality mapping

$$
\mathrm{U}^{*}(\mathbf{x}, \mathbf{z}, \mathbf{r})=\min _{\mathrm{p}} \mathrm{V}(\mathbf{p} \cdot \mathbf{x}, \mathbf{p}, \mathbf{z}, \mathbf{r})
$$

to obtain a reduced form utility function of the market goods. Then $\mathrm{U}^{*}$ has the conventional properties of a neoclassical utility function. This construction does not require convex preferences and household production possibilities, and leaves household production implicit. Then, by Occam's razor, if only market purchases are observed, one might as well model only $\mathrm{U}^{*}$, and treat household production as outside the province of economics. However, there is potentially a great deal to be learned when it is possible to measure some post-household-production hedonic quantities. Variation in household technologies may be a source of apparent taste variation in utility, or may attenuate the impact of taste variations on market transactions. Structural models of household production and consumption can explain simply behavior that may otherwise be difficult to interpret, such as demand for education, exercise, work, and household durable equipment that has both consumption and production aspects. The hedonic measures $\mathbf{w}$ may be conventional economic ones, like horsepower and cargo space, or may be proximate to the organism; e.g., calorie intake or alleostatic load. Careful analysis of household production, augmented by hedonic measurements, is in my opinion one of the promising and relatively neglected frontiers in econometric study of consumer behavior. The utility maximization (22) is a problem of utility maximization subject to a non-linear budget constraint, as discussed in the previous section; in this case, the hedonic content of market goods and the household technology define the nonlinear budget in $\mathbf{w}$. Then, linear additive 
perturbations in marginal utility and/or linear additive perturbations in the cost of meeting household output requirements can be used in dual characterizations of production and utility.

Hedonic regressions of product prices on attributes were introduced by Zvi Griliches and Irma Adelman (1961) as a method of adjusting price indices to control for product quality. ${ }^{16}$ These regressions were later connected by Sherwin Rosen (1974) to the theory of utility maximization and market equilibrium in hedonic space; see also Makoto Ohta (1971), Ohta and Griliches (1986), Ivar Ekeland (2010), Andreu Mas-Colell (1996), McFadden (2008), and, and Heckman-Matzkin-Neshelm (2010). In summary, this literature finds that existence of stable equilibrium in markets with differentiated hedonic commodities is problematic, that structural identification is difficult even when equilibrium is well-defined, and that an equilibrium mapping from hedonic content to price is in general a nonparametric reduced form that reflects technology and market structure as well as consumer preferences. Nevertheless, both McFadden and Heckman-Matzkin-Neshelm give conditions under which it is possible to recover the distribution of hedonic preferences when consumers operate at active margins, locating at observable points in hedonic space in response to tradeoffs between hedonic factors.

I will give one example in which a linear regression of the log of market good price on a vector of observed hedonic content identifies consumer tastes for hedonic attributes. Assume that consumers have utility functions $\mathrm{U}(\mathbf{w}, \mathbf{r})$ of a vector $\mathbf{w}=\left(\mathrm{w}_{1}, \ldots, \mathrm{w}_{\mathrm{K}}\right)$ of hedonic quantities, and associated indirect utility functions $\mathrm{V}\left(\mathbf{p}^{*}, \mathrm{y}, \mathbf{r}\right)$ of the effective prices $\mathbf{p}^{*}$ of hedonic units. Assume the first hedonic quantity is a sum of quantities of $\mathrm{m}$ market goods, weighted by their hedonic content, $\mathrm{w}_{1}=\mathrm{x}_{1} \exp \left(\mathbf{z}_{1} \beta+\varepsilon_{1}\right)+\ldots+$ $x_{m} \exp \left(\mathbf{z}_{m} \beta+\varepsilon_{m}\right)$, where $\beta$ is a vector of taste weights, $\mathbf{z}_{j}$ describes the measured hedonic content of good $j$, and $\varepsilon_{\mathrm{j}}$ summarizes unmeasured hedonic attributes of good $\mathrm{j}$. Note that the hedonic attributes enter in a

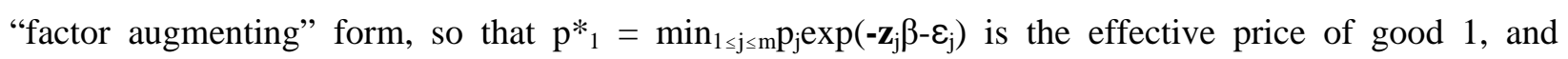
$\mathrm{V}\left(\min _{1 \leq \mathrm{j} \leq \mathrm{m} \mathrm{P}_{\mathrm{j}}} \exp \left(-\mathbf{z}_{\mathrm{j}} \beta-\varepsilon_{\mathrm{j}}\right), \mathrm{p}^{*}{ }_{2}, \ldots, \mathrm{P}^{*}{ }_{\mathrm{k}}, \mathrm{y}, \mathbf{r}\right)$ is the consumer's indirect utility expressed in terms of the market prices and hedonic content of the market goods $1, \ldots, \mathrm{m}$. Suppose the consumer faces a consumption set $\mathbf{X}$ in which she can buy the market goods $1, \ldots, \mathrm{m}$ in continuous quantities. The optimizing consumer will then purchase only market goods in $\operatorname{argmin}_{1 \leq \mathrm{j} \leq \mathrm{m} \mathrm{P}_{\mathrm{j}}} \exp \left(-\mathbf{z}_{\mathrm{j}} \beta-\varepsilon_{\mathrm{j}}\right)$. If all consumers are identical in their hedonic taste weights $\beta$ and perceptions of the unobserved attributes $\varepsilon_{\mathrm{j}}$, then all goods observed in the market will have effective prices achieving the minimum, so that $\log p_{j}=\alpha+\mathbf{z}_{j} \beta+\varepsilon_{j}$ for $j=1, \ldots, m$, where $\alpha$ is a (random) value common to all the goods. Then with these strong assumptions on preferences,

\footnotetext{
${ }^{16}$ The typical hedonic regression for commodity like housing is $\log p=\mathbf{z} \beta+\varepsilon$, where $p$ is price, $\mathbf{z}$ includes observed attributes such as square footage, age, number of baths, and proximity to schools, jobs, and environmental nuisances, and unobserved attributes combine into a disturbance $\varepsilon$.
} 
market prices for the goods $1, \ldots, \mathrm{m}$ are determined independently of production and market structure, and the hedonic regression parameters are preference weights.

A discrete choice variant on the setup above also allows econometric recovery of hedonic taste weights. Suppose now that the consumption set $\mathbf{X}$ requires the consumer to choose a unit purchase from mutually exclusive alternatives $1, \ldots, \mathrm{m}$, and consumers have common taste weighs $\beta$ but are heterogeneous in their perceptions $\left(\varepsilon_{1}, \ldots, \varepsilon_{\mathrm{m}}\right)$ of the unmeasured attributes. Then, the share of consumers choosing alternative $\mathrm{j}$ is given by a discrete choice model,

$$
\operatorname{Prob}\left(\mathrm{j} \mid \mathrm{p}_{1}, \ldots, \mathrm{p}_{\mathrm{m}} ; \mathbf{z}_{1}, . ., \mathbf{z}_{\mathrm{m}}\right)=\int \mathrm{F}_{\mathrm{j}}\left(\left(\mathbf{z}_{\mathrm{j}}-\mathbf{z}_{1}\right) \beta-\log \left(\mathrm{p}_{\mathrm{j}} / \mathrm{p}_{1}\right)+\varepsilon_{\mathrm{j}}, \ldots,\left(\mathbf{z}_{\mathrm{j}}-\mathbf{z}_{\mathrm{m}}\right) \beta-\log \left(\mathrm{p}_{\mathrm{j}} / \mathrm{p}_{\mathrm{m}}\right)+\varepsilon_{\mathrm{j}}\right) \mathrm{d} \varepsilon_{\mathrm{j}}
$$

where $F$ is the cumulative distribution function of $\left(\varepsilon_{1}, \ldots, \varepsilon_{\mathrm{m}}\right)$ and $\mathrm{F}_{\mathrm{j}}$ denotes its derivative with respect to its $\mathrm{j}^{\text {th }}$ argument. If, for example, $\mathrm{F}$ is i.i.d. extreme value, then (24) is multinomial logit, the specification used in my initial formulation of discrete choice models (Domencich and McFadden, 1975; McFadden, 1974ab).

Both hedonic regression and hedonic discrete choice have had wide application, and have been generalized to nonlinear, semiparametric, and nonparametric specifications; see, for example, Anderson, de Palma, and Thisse (1992), McFadden and Train (2000), Yatchew (1998, 2003), Heckman, Matzkin, Neshelm (2010). An econometric issue, tacit in both hedonic regression and discrete choice models, is that the orthogonality or independence of observed hedonic attributes and unobserved disturbances is problematic. Traditional instrumental variables methods usually suffice for linear hedonic regression, but nonlinear models are more challenging, and have been the subject of a large literature; see, for example, Berry-Levinsohn-Pakes (1995, 2004), Berry-Linton-Pakes (2004), Blundell and Powell (2004), Matzkin (2005,2008).

VI.4. Consumer Dynamics. When consumer behvaior is considered over time, it is necessary to clarify what utility and utility-maximization mean. One concept is that of instant utility or felicity, a hedonic index of the sensation of well-being at a moment. Another is decision utility, an index of the desirability of choices that may be available at the moment and that determine current consumption and future options. A third is remembered utility, an index of current satisfaction with experiences in the past. Neoclassical economics focuses on decision utility as the operative driver of market behavior, and emphasizes that only its ordinal properties matter. In this view, instant utility and remembered utility are relevant to economic behavior only through their influence on decision utility, even if they have independent psychological content. 
The major issues in neoclassical modeling of consumer behavior over time were the intertemporal structure of decision utility, and the event timing, information sets, and calculus involved in utility maximization. Consumer theory has handled these in two ways. A framework introduced by Fisher (1908, 1930), Edmund Malinvaud (1953), and Gerard Debreu (1959) dated commodities and made their delivery contingent on uncertain events. In Debreu's interpretation, utility spanned the lifetime of the consumer, with a single decision-utility-maximizing choice specifying in advance the response to the realization of each contingency, and determining the entire life course. This was a complete, logically elegant, and instructive implementation of consumer theory, with utility incorporating a complete system of perceptions and subjective probabilities, and including in the life plan of the consumer full allowance for the strategic impact of choice on later options and preferences. Nevertheless, the approach has severe limitations, first because its full articulation requires the existence of a spanning set of contingent markets that in practice do not exist, but more fundamentally because it is clear from behavioral evidence that life plans are "incomplete contracts" that ignore many contingencies and are subject to continual updating and revision. The limits of the approach are obvious when one asks at what point in time the consumer's once-and-for-all life choice is made - at birth, the time of preparation for A-level exams, voting age?

The second approach to handling time and uncertainty in neoclassical consumer theory was to treat the utility of a life as the integral of discounted instant utilities, an idea that dates back to Bentham's depiction of utility as depending on intensity, duration, and propinquity or remoteness, and to Edgeworth's description in 1881 of the level of happiness associated with an experience as the integral of the intensity of pleasure over the duration of the event:

"The continually indicated height [of felicity] is registered by photographic or other frictionless apparatus upon a uniformly moving vertical plane. Then, the quantity of happiness between two epochs is represented by the area contained between the zero-line ... and the curve traced by the index.”

Edgeworth viewed felicity as a cardinal measure of sensation, with levels that were comparable across time and allowed utility to be expressed as an integral. The later neoclassical formulation instead deduces felicities as a feature induced by a separability property of preferences (see Debreu, 1986). The formulation of decision utility as an integral of felicities is usually extended to decompose the utility of uncertain prospects into the expected utility of their outcomes under the axioms of von Neumann-Morgenstern (1953) and Savage (1954); see Arrow (1971). To complete the theory, it is necessary to describe how the utility function depends on memory and learning, how perceptions and subjective probabilities are formed and updated, and how choices are made and revised as time passes and events unfold. A typical implementation assumes that the consumer solves a dynamic stochastic program 
to maximize the expected present value of a discounted integral of future instant utilities, with subjective probabilities that satisfy the Muth-Lucas axiom of rational expectations, requiring that subjective probabilities of different consumers agree with objective frequencies, and hence with each other; see Muth (1992, 1994), Lucas (1975). The approach can accommodate experience and learning through state variables that enter instant utility, but often these effects are omitted or admitted in very restrictive form. The dynamic stochastic programming approach is again an elegant and instructive logical solution to the problem of consumer dynamics. However, the strongest form of the model, with a representative consumer and rational expectations, is vulnerable to behavioral rejection, because the solution of these programs involve levels of complexity and computation that fairly clearly exceed human cognitive capacity, because it is unrealistic to assume that historical experience and market information and discipline are sufficient to homogenize subjective expectations, particularly for rare events, and because the axiomatic foundations for utility jointly additively separable in time and uncertain outcomes are not persuasive; see Pollack (1970).

Intertemporally separable decision utility has difficulty explaining the smoothness of consumption in the presence of observed income shocks; e.g., Hall (1978), Campbell and Deaton (1989), Sundaresan (1989), Okubo (2002), Attanasio and Pavoni (2011). This is most easily addressed within the neoclassical framework by letting felicity depend on state variables that summarize consumer history. In addition to observed states, such as holdings of consumer durables, allow unobserved or hidden states that carry the effects of intertemporal substitutability. By expanding the dimensionality of the state description, the utility maximization model can be represented as a dynamic stochastic program with Markov dynamics.

A final generalization would be to reintroduce the idea of Jevons and Edgeworth (1896) that the same objective time may correspond to different rates of thought and feeling in different periods, so that two dimensions are required to characterize the elements of the utility of an episode, its felicity and subjective time. Then, decision utility at moment $t$ would have the form

$$
\mathrm{u}=\mathbf{E}_{\mathrm{t} \mid \mathbf{z}(\mathrm{t}), \mathbf{s}(\mathrm{t})} \int_{t}^{\infty} \mathrm{U}(\mathbf{x}(\tau), \mathbf{z}(\tau), \mathbf{s}(\tau), \mathbf{r}) \delta(\mathrm{d} \tau, \mathrm{t}, \mathbf{z}(\mathrm{t}))
$$

where $\mathbf{x}(\tau)$ is the vector of market goods purchased at time $\tau, \mathbf{z}(\tau)$ is the consumer's environment, $\mathbf{s}(\tau)$ is a vector of observed and hidden state variables, and $\mathbf{r}$ indexes tastes. The function $\mathrm{U}(\mathbf{x}(\mathrm{t}), \mathbf{z}(\mathrm{t}), \mathbf{s}(\mathrm{t}), \mathbf{r})$ is felicity at $\mathrm{t}$, and $\delta(\mathrm{d} \tau, \mathrm{t}, \mathbf{z}(\mathrm{t}))$ measures a subjective time interval at $\tau$ as viewed from the current moment $\mathrm{t}$. In this formulation, subjective time may depend on the environment of the consumer. The measure $\delta$ also incorporates time and risk discounting, which arises in the utilitarian view because, in the words of 
Edgeworth, "the bird in the bush may never come to hand". The operator $\mathbf{E}_{t \mid \mathbf{z}(\mathrm{t}), \mathbf{s}(\mathrm{t})}$ denotes subjective expectation at $\mathrm{t}$, conditioned on the consumer's environment and experience at that moment. The state $\mathrm{s}$ has an equation of motion

$$
\mathrm{ds}(\mathrm{t}) / \mathrm{dt}=\mathrm{h}(\mathbf{x}(\mathrm{t}), \mathbf{z}(\mathrm{t}), \mathbf{s}(\mathrm{t}))
$$

This formulation of decision utility, embedded in a dynamic stochastic program, and allowing heterogeneity in preferences and perceptions, and interactions between perceptions, tastes, and experience, is an extension of the neoclassical consumer model that can accommodate phenomena such as "time-inconsistent discounting”, "time-inconsistent perceptions”, and differences between a direct integral of felicities and either remembered or decision utility. If the state $\mathbf{s}(\mathrm{t})$ includes time averages of $\mathbf{x}$, and these time averages establish reference points or aspiration levels for the consumer, then the utility function can capture asymmetric hypersensitivity to gains and losses from these reference points. This setup risks explaining too much, including Taussig's purchases made on a whim, but it can be given content by restricting the structure of felicity, subjective time, and subjective expectations.

\section{New Frontiers: A Behavioral Revaluation of Consumer Decision-Making}

Neoclassical consumer theory implies that with rational calculation, we cannot be harmed by choice and trade. Then people should relish choice, and welcome all the alternatives offered by markets. Yet, people are challenged by choice. In the words of a Dutch proverb, "He who has choice has trouble". We find choice uncomfortable, and often use procrastination, rules, pre-commitment, habit, suspicion, and imitation to avoid "rational” decision-making and trade. The psychiatrists even have a word for it agoraphobia, or fear of the market. There are two possible reasons for this behavior. First, while trade is calculated to advance our self-interest, the calculation may be burdensome, and the cost of mistakes substantial. We may simply be too lazy or timid to trade. Second, trade involves social interaction and the emotions that go with this. Choice alternatives and trades may be misrepresented in the market game, and suspicions may be justified. As a result, we evaluate economic activities not only cognitively, but also strategically and viscerally; see Mellers (2000), Lowenstein (2003), McFadden (2006). This emotional aspect not only explains why economic choices can make us uncomfortable, but also why we sometimes make systematic mistakes - we do not approach economic decisions with a single mind.

\section{FIGURE 3 ABOUT HERE}

A schematic for behavioral models of choice, given in Figure 3, differs from the neoclassical schematic primarily by adding affect and motivation as factors in choice, relaxing the rigid requirement that 
preferences are sovereign and king of the sentiments, and adding possible feedbacks. However, there is a more fundamental difference. Neoclassically trained economists think of these behavioral elements as arising from the limits of memory and cognitive capacity that bound rationality, slips or anomalies that the individual will detect and correct if they become obvious. Many psychologists and biologists think of this instead as a product of evolution, the result of a rough correspondence between generalized self-interest and survival, a hodge-podge of rules, processes, and strategies that mimic rationality in circumstances where rationality increases survival value. Day-to-day economic choices are explained by either paradigm, but perception and choice in novel situations tests the neoclassical premise, and challenges easy transitions between conventional demand analysis and the effect of novel economic policy on consumer well-being.

Measurement of economic consumer behavior will continue to center on studies of revealed market behavior, with traditional consumer expenditure surveys augmented by electronic tracking of consumer purchases through scanner data, high frequency sampling through internet panels, and increasing exploitation of natural experiments. These measurements will be supplemented by analysis of stated choices in hypothetical markets, and a great deal more data from microeconomic surveys, experimental economics, marketing science, and cognitive psychology. Perhaps the most interesting and challenging new measurements come from fields not commonly allied with economics, sociology, anthropology, evolutionary and cellular biology, and neurology. I will give an overview of this research, starting with more traditional psychological measurements and experiments in cognitive psychology, then measurements and experiments in sociology and anthropology, and concluding with findings and experiments in biology and neurology.

VII.1. Stated Preferences and Conjoint Analysis. Lack of observed variation in attributes of market goods, and issues of exogeneity, have led economists to consider information obtained from hedonic preference experiments with hypothetical market choices. This is the method of conjoint analysis, adapted in market research from its psychophysical roots (Thurstone, 1931; Luce and Tukey, 1964; Johnson, 1974; Green et al, 1981; McFadden, 19986; Green et al, 2001), and tied to models of stochastic preferences as a result of econometric work on discrete choice models (McFadden, 1986; Morikawa, Ben-Akiva, McFadden, 2002). In a review of consumer demand experiments, Ivan Moscati (2007) gives a remarkable bit of intellectual history. The first conjoint experiment on consumer demand was done by the iconic psychologist Leon Thurstone at the urging of his University of Chicago colleague Henry Schultz. Thurstone presented his paper at the 1932 meeting of the Econometric Society, with Ragnar Frisch and Harold Hotelling commenting from the audience on the critical differences between hypothetical and real choices. Thurstone's method was noted and dismissed by Nicholas Georgescu-Rogen (1936) and by Allen 
Wallis and Milton Friedman (1942) for three compelling reasons, the hypothetical nature of the offered choices, the difficulty of detecting indifference, and the difficulty of controlling experimentally for the effect of income and prices. Thurstone is not mentioned in the neoclassical treatises of Hicks and Samuelson, and there were no economists involved in the initial applications of conjoint analysis in marketing. However, abbreviated versions of conjoint analysis, termed contingent valuation, vignette analysis, or self-reported preference, later became popular among some applied economists and political scientists; see Rossi (1979), McFadden (1986,1994), Diamond and Hausman (1994), Green et al (1998), Carson et al (2001), Frey et al (2002), King et al (2004). The use of hypothetical market choice data remains controversial among economists, with some reason, as it is difficult to achieve the verisimilitude of real markets in the laboratory, and cognitive inconsistencies that are not obvious in low-frequency real market choices may be glaring in repeated laboratory choices.

A number of mechanisms have been developed for incentive-compatible elicitation of preferences; McFadden (2010) shows for example how the Clark-Groves mechanism can be used in an economic jury drawn at random from the population to decide on public projects. However, in practice many stated preference elicitations are either not formatted to be incentive-compatible, or fail to carry through to the payoffs required in an incentive-compatible mechanism. Consequently, responses are likely to be distorted by inattention, risk preference, and careless opinion.

Despite these weaknesses, stated preference methods have become a proven tool in marketing for designing and positioning new products. For example, experiments on automobile brand choice can determine with considerable predictive accuracy the distributions of preference weights that consumers give to various vehicle features; see Urban et al (1990, 1997); Toubia et al (2003); Train and Winston, (2005). In overview, experience seems to be that these methods work best when the task is choice among a small number of realistic, relatively familiar, and fully described alternative products, ideally with the incentive that with some probability the offered transaction will be executed and the stated choice delivered. Stated preference methods are less reliable and less directly useful for predicting behavior when the task is to rate products on some scale, or to adjust some attribute (e.g., price) to make alternatives indifferent. They are also less reliable when the products are unfamiliar or incompletely described, or involve public good aspects that induce respondents to make social welfare judgments. Methods that require cardinal utility judgments, such as those of the Leiden school (van Praag and Kapteyn, 1994) and Frey and Stutzer (2002), have intuitive validity, but require strong behavioral axioms to be consistently predictive for choice; see Dagsvik (2005).

A neglected area related to stated preferences are elicitations of stated perceptions. Manski $(1991,2004)$ and others have developed elicitation methods that avoid some obvious distortions in stated 
personal probabilities, and appear to explain some risk-taking behavior. A useful extension of current conjoint methods would be to incorporate and measure subjective perceptions and other psychological dimensions that appear to influence decision-making.

VII.2. Measurements from Cognitive Psychology. There are now extensive experiments and insights from cognitive psychology that contradict a narrowly defined neoclassical model of rational choice, many originally conducted by Amos Tversky and Danny Kahneman. These suggest that preferences are malleable and context-dependent, that memory and perceptions are often biased and statistically flawed, and decision tasks are often neglected or misunderstood. Table 2 is a summary of major cognitive anomalies that appear in psychological experiments and surveys; for more details, see Rabin (1998), McFadden (1999). I will give four examples of anomalies that challenge the neoclassical model.

VII.1.1. The endowment effect is consumer aversion to trade from any given status quo. The endowment effect was beautifully illustrated in a classical experiment by Jack Knetsch (1989) in which a random assignment of coffee cups produced a large gap between WTP and WTA, with far less trading than should be needed to move from a random allocation to a Pareto efficient one; see also Kahneman, Knetsch, Thaler (1990,1991), Camerer and Thaler (1995). I conducted a comparable experiment in an introductory microeconomics course at Berkeley, using pencils embossed with the course name. About half of the 345 students, 172, were randomly endowed with a chit redeemable for a pencil. Then, a Vickery sealed-bid uniform price double auction (Yoon, 2001) was held to reallocate the chits: If the participants had true values $v_{1} \geq \ldots \geq v_{345}$, then the optimal strategy for each player was to bid her true value, and chits awarded to people with values less than $v_{172}$ should trade, with buyers paying $v_{173}$, sellers receiving $v_{172}$, and the market manager covering the difference. The income effect of being endowed with a pencil is negligible, so that with random assignment the distributions of money marginal utilities of a pencil should be the same for buyers and sellers. Then if there were no endowment effect, one would expect about one-half the pencils to trade at a price close to the median values for both buyers and sellers. More precisely, the number of chits awarded to the 173 students with the lowest value, which we expect to be traded, has a hypergeometric distribution with mean 86.2 and standard deviation 4.6.

The experimental results are summarized in Figure 4. The market cleared with 32 chits traded, at a price of 35 cents. The median of the sealed bid prices was 10 cents, while the median of the sealed ask prices was 100 cents, a gap between WTP and WTA similar to that found in the cup experiment. The probability of 32 transactions or fewer when there is no endowment effect is on the order of $10^{-16}$. Further, a runs test confirms $(\mathrm{T}$-Stat $=12.5)$ that buyers and sellers do not have the same value distribution. Thus, there is a strong, trade-suppressing endowment effect, generated instantaneously by a random allocation of 
pencil chits. Either values are changing endogenously, with almost instantaneous habituation to the status quo, or agoraphobia is real -- consumers find trade an edgy experience, instinctively mistrust the market, and resist trading for small gains.

VII.1.2. Choice among lotteries often deviates from rationality; see Gilovich et al (2002), Langer and Weber (2001). A stylized summary is that consumers display (i) an endowment effect, evaluating lotteries as changes from a reference point that may be sensitive to framing, (ii) an asymmetric loss aversion effect, in which the consumer is more sensitive to losses than to gains, displaying risk aversion for small gains and risk seeking for small losses, and (iii) a certainty effect in which sure outcomes are overvalued relative to lotteries. In addition, there are (iv) an isolation or cancellation effect in which common aspects of alternative lotteries are ignored when they are compared, (v) a segregation effect in which a riskless component of a lottery is evaluated separately from the risky component, and (vi) a mode effect in which pricing a lottery is treated as a qualitatively different task than choosing between lotteries. One of the consequences of these effects is that consumers will often refuse to take any share of either side of an offered lottery, a result consistent with the observed paucity of real-world wagers. Kahneman and Tversky attribute these effects to an editing process that determines the reference point and the perception of lottery outcomes as gains or losses, and to systematic misperception of probabilities. An additional reason that individuals are ambiguous about lotteries, and often avoid them, is the superstitious belief that there are hidden causal forces at work, interventions that place the lottery in ambiguous relationship to the rest of life. People often have strong beliefs that they are lucky, or unlucky, or that their luck has to change. We have selective memory for coincidences. You remember running into a friend at a surprising place, or a particularly good night a poker; you forget all the times you did not encounter a friend or had an unremarkable night. Chance jolts the harmony of conscious belief; relief from this dissonance is gained by imposing an order over chaos, weaving a fabric of apparent cause and effect, out of jumbled coincidences. The mind accepts and emphasizes those coincidences which reaffirm one's perceived order of the universe, ignores and forgets inconsistent data, and shrouds each offered lottery in ambiguity regarding hidden effects. Superstition can arise and persist even when people are consistently Bayesian. Start with a prior that admits the possibility of complex, hidden causal paths. The experiments that life offers, and selective memory of outcomes, allows these cognitive castles in the air to survive; see McFadden, 1974c; Hastie and Dawes, 2001.

These is experimental evidence that endowment effects are attenuated when traders are experienced; see Myagkov and Plott (1997), List (2004). Thus, the observed paucity of trades in lotteries may occur primarily for novel events and inexperienced traders. These facts are consistent with a proposition that 
learning by observing and by doing may be effective in selecting rational market behavior rules in arenas with sufficient repetitiveness to allow these effects to operate.

VII.1.3. Hyperbolic discounting occurs when individuals systematically underweight future consequences relative to contemporaneous ones, and make choices that gratify now and leave lasting regret, in patterns that cannot be explained by maximization of consistently discounted present value of instantaneous utility. If one thinks of the current instance as a reference point in time, then this phenomena resembles those surrounding the endowment effect, with the future neglected because it is ambiguous and difficult to anticipate, and lacks saliency. As discussed in Section VI.4, a utilitarian rationalization of hyperbolic discounting, dating back to Jevons, is that the experience of time is subjective, so that a ten-minute interval now is subjectively longer than a ten-minute interval a week in the future.

VII.1.4. A remembered utility effect occurs when memory of a painful or pleasurable episode is dominated by sensation at the peak and the end of the episode, rather than being determined as an integral of experienced intensities over the duration of the episode. A related phenomenon in psychology is labeled the primacy/recency effect. We remember the first and last instances of some significant experience, less well the intermediate and integrated experience. An implication of these features of recall is extension neglect - the comparison of two episodes that differ in duration will tend to neglect duration.

For example, a study by Donald Redelmeier and Kahneman (1996) of experienced pain during colonoscopies, and recall of the episode, finds that adding pain of reduced intensity at the end of an episode improves overall recall of the experience; see also Varey and Kahneman (1992), Huber et al (1997). Kahneman, Wakker, and Sarin (1996) document in a number of experimental settings this phenomenon of duration neglect and concentration on recent experience, what one might call hyperbolic memory.

A deeper reason for the phenomena of hyperbolic discounting and remembered utility is given by the psychologist George Lowenstein (1996) -- it is difficult to recall or anticipate affective or emotional state. We may remember being in pain, and have a strong aversion to the antecedents of a painful experience, but we cannot relive the experience itself. Consequently, we may forget affective history, and fail to adequately protect ourselves against repeating it. Duration neglect can be recast in a neoclassical model with subjective time. Whether this is leads to parsimonious, predictive models, or experiments on these effects can be designed that give results inconsistent with any intertemporal utility model, remains an open question. 
VII.2. The Sociality of Choice. Man is a social animal, identified with family and kin, and with clubs, troupes, tribes, ethnicities, and nationalities. This has several consequences for economic choice behavior. First, individuals may look to their social networks for information. Second, they may look to social networks for approval, and use accountability to limit choice. Third, they may out of pure self-interest engage in mutually beneficial reciprocity, simple when the acts are synchronous, involving more complex elements of reputation and trust when they are not. Pursuing comparative advantage, with division of labor and trade, is a form of reciprocity. Fourth, they may engage in genetic altruism, making choices that are in the interest of their progeny rather than themselves as individuals. Fifth, they may exhibit altruistic behavior that does not obviously serve their personal or genetic self-interest, such as incurring costs to sanction greedy behavior. There is a large literature in economics about the sociality of consumption, from Dusenberry on relative consumption and the sensitivity of savings behavior to relative income within a society and relative insensitivity to its absolute level of income, to conspicuous consumption, fads, and bandwagon effects. However, while sociality has been recognized as important, the mechanisms of its operation have been obscure, and it has not led to a simple formalization comparable to that for conventional demand theory; these questions are explored further in McFadden (2010).

VII.2.1. One major way sociality may work is simply through transmission of information, learning by imitation rather than learning by doing. People constantly make interpersonal comparisons, judging the desirability of options from the apparent satisfaction and advice of others. While personal experience is the proximate determinant of the utility of familiar objects, and may be extrapolated to similar objects, our primary sources of information on new objects come from others, through observation, advice, and association. McFadden \& Train (1996) show that in innovation games with uncertain payoffs, it may pay to wait, and learn by observing rather than learn by doing. Manski (1991) has explored the possibility that individuals faced with dynamic stochastic decision problems that pose immense computational challenges may simply look to others to infer valuation functions to be used to judge the future payoff of current acts, or to infer satisfactory policies. An objection to such copycat behavior is that it fails to take account of the individual's idiosyncratic tastes, and correcting this quickly gets the individual back into the computational difficulties that imitation was intended to circumvent. But if tastes as well as perceptions are modified socially, the relevance and value of the lessons from others increases.

VII.2.2. Economic demographer Hans Peter Kohler (2001) has investigated the effect of word-of-mouth communication from friends on choice of contraceptive. He studies Korean peasant women, who have access to relatively little public information on efficacy, costs, and side effects of new 
contraceptives. Choices within villages show little diversity, but there is substantial, persistent diversity across villages. This pattern not explained by income, education, or price differences.

Word of mouth communication from friends was found to be the important explanation of most women's choices. Lack of inter-village mobility explained multiple equilibria, with persistent inter-village differences. Thus, some apparent taste heterogeneity is due to the boundedly rational practice of imitation in balkanized social networks. The moral is that any complete measurement system for consumer behavior must account for social network effects. Suggestions for measurement are that stated perceptions and preferences should be conditioned on the behavior of members in an individual's social network, and the distribution of consumption in social equilibrium should be modeled as the (often non-unique) solution to a game in which choices of peers matter.

VII.2.3. In addition to providing information, social networks may discipline the behavior of members through consensus on social norms, accountability for choices, and sanctions for behavior that violates norms. The individual gains from affiliation with such networks if imitation and conformity save energy, if the "expectation that one will be called upon to justify one's beliefs, feelings, or actions, to others" improves decision-making, and if approval is itself a source of pleasure. We engage in a great deal of automatic or intuitive thinking, or one might say semi-conscious or background thinking, in daily decisions. For example, an experienced driver does not go through a conscious process of deciding to change lanes. Automatic thinking saves energy, and time. The classical idea of herd mentality is that social animals find it easier and more comfortable to adhere to a group, accept group roles, and mimic group behavior than to act independently. Accountability reinforces herd mentality in fixed groups, and promotes safety in numbers. Individual membership may be voluntary, as in the peloton of tightly packed riders in a bicycle race, with riders tightly clustered and constrained in order to save energy in preparation for "breakaways". The lack of well-defined measures for social norms and accountability are a significant barrier to modeling their influence on utility and on social equilibria, but clearly natural or laboratory experiments in which the social environment of market behavior is manipulated can be used to test for the effect of social pressures in various contexts.

VII.2.4. Reciprocity is a simple form of social interaction, present in economic trade and explained by self-interest. Reciprocity is simple to establish when it is synchronous, as in bilateral barter. However, asynchronous reciprocity requires reputation and trust. In the words of Kenneth Arrow, "Trust is an element in every commercial transaction". 
Norms for fair practice, and sanctions for bad behavior, may evolve in social networks to facilitate asynchronous reciprocity, and individuals may by habit or internalization conform to these norms even in novel situations where the normal cycle of approval and reputation is suspended. Consider the single-shot ultimatum game with anonymous players: Player 1 proposes a division of a prize of 100 units. If Player 2 accepts, the players get the proposed shares; otherwise, they get nothing. It is rational for Player 2 to accept any positive amount, and thus rational for Player 1 to offer the minimum positive amount. However, if the probability of acceptance a(s) by player 2 is less than one when the share s offered by player 1 is low, then player 1's optimal strategy is to maximize a(s).(1-s). Students in a cross-section of developed countries play similarly, but not rationally. Offers are usually 42 to 50 percent of the prize, and offers less than 20 percent are rejected about half the time. These results are consistent with behavioral rationality for the first player if for example $\mathrm{a}(\mathrm{s})=\min (1,2.5 \cdot \min (\mathrm{s}, 0.2)+6 \cdot \max (\mathrm{s}-0.2,0))$. Whether stated beliefs of Player 1 regarding acceptance by Player 2 would be consistent with this a(s), or another function that rationalizes Player 1 behavior, is an open question.

VI.2.5. Isolated cultures offer natural experiments for testing the impact of social norms on trust and reciprocity. Sam Bowles and a team of experimental economists and ethnographers have conducted anonymous ultimatum game experiments in 15 isolated societies; see Henrich et al (2004), Bowles and Gintis (2011). Four of these are the Lamalera, a cooperative whale-hunting culture in Indonesia; the Ache, seasonal foraging bands in Paraguay that have some exposure to markets; the Hadza, hunter-gatherer bands in Tanzania; and the Machiguenga, horticultural family groups in Peru. The research finds strong cultural differences, shown in Table 3, with large mean offers among the Lamalera, who have ritualized rules for cooperation and sharing, and low mean offers among the Machiguenga, who have little experience in interaction outside the family. Within a culture, lower offers generate more rejections, but willingness to incur the cost of rejecting an offer differs substantially across cultures. The research concludes that violation of the selfishness axiom is common across cultures, but with differences that are a product of the social and economic lives of the subjects. The more integrated and market-oriented the contacts between individuals, influenced by the technologies available for subsistence, the stronger a norm for "fair play", and the more willing respondents to punish selfish behavior at a cost to themselves.

VII.2.6. Genetic Altruism is the phenomenon of self-sacrifice for the good of your family or kinship group. Genetic altruism appears to explain cooperation in most species, and appears to have a convincing evolutionary basis. William Hamilton (1964), an icon of sociobiology, wrote

"The force of evolution favors "selfish" genes, those that promote their own reproduction. Individuals do not consistently do things for the good of their group, their family, or even themselves. They consistently do things for the good of their genes." 
Matt Ridley (1996), in an entertaining account of the evolution of sociality, wrote "None of your ancestors died celibate.”

The principles of selection and genetic altruism infuse classical economics. However, despite their recognized importance, particularly in economic models of the family and of intergenerational transfers, they were not systematically studied as determinants of economic behavior; see Becker (1976), Koszegi (2004). The operation of genetic selection in promoting a disposition toward altruism could be very indirect. Thus, the acquisition of language, the exploitation of comparative advantage, the formation of successful defenses against marauders and disease, and a disposition to "fair play" that reduces interpersonal conflict, may all arise from the selective advantage to group traits that promote sociality. Then altruistic behavior, including gifts to unrelated individuals with no possibility of personal gain, might be explainable as an indirect consequence of genetic self-interest. If so, the center of the original utilitiarian concept of relentless pursuit of pleasure could still hold, with group selection leading to the real, selfish pleasure we get from altruism.

Paul Samuelson (1994) demonstrated that group selection works if the advantages of altruism are sufficient to offset a Gresham's law of individual selection, in which altruistic traits are driven out by antagonistic selfish traits. However, experimental studies of altruistic punishment collected and carefully interpreted by Ernst Fehr and colleagues (2002, 2005) suggest that evolutionary pressure for group selection is not consistent enough, and the costs of altruistic punishment in large groups are too high, to explain the pervasive and distinguishing level of altruism in large human groups. His conclusion is that human altruism is a mystery that selfish genes and selection cannot fully explain, something about our wiring that may not fit the notion of utility calibrated to experience pleasure from genetic survival. What is important for a discussion of the measurement of well-being is to understand that whatever its roots, our perceptions of the well-being of others do affect our own behavior and well-being, in ways that may be explained in part by genetic altruism and group selection even if other causes are buried deeper in the human makeup; see Zamagni (1995).

VII.3. Sensation and Neuroeconomics. Brain science offers a new frontier for consumer measurements, through identification of reward structures and neurotransmitters in the brain, and study of the impact of choice problems on the brain in the presence of experimental treatments. Brain measurements include maps of energy consumption (fMRI and PET tomography), electrochemistry (probes, peptides, and radionucleides), and physical intervention (gene manipulation, structural manipulation in animals, and natural experiments in brain-damaged humans). In tandem with behavior 
intervention (manipulation of the choice environment, measurement of response), brain measurements provide information on the cognitive processing structure, perceptions, and sensations associated with choice. They fall considerably short of Edgeworth's wistful call for a hedinometer to measure pleasure, but they provide some functionality and insight into the sensations that economists call utility.

The early biologists observed that as the human embryo developed, it seemed to go through stages of evolution, from a simple one-celled creature to its complex final form. That view was superficial, but it does seem to be the case that human physiology, and in particular, the structure of the brain, is consistent with a layering of added functionality over a simpler and more primitive core. The aspects of brain function that we identify with being human - language, the cognitive processes of deduction and induction, the ability to empathize and interact with others, are primarily sited in frontal lobe of the cerebrum, the outer layer of the brain whose relative size and complexity in humans differentiate us from most other species. The more basic limbic system, buried at the base of the cerebrum, is heavily involved in emotion and the reward pathways that are associated with sensations of pain and pleasure. This system includes the amygdala, sometimes termed the "switchboard of the brain", which is particularly rich in reward pathways and is active in animal behavior at a visceral level: approach and avoidance, foraging, territory, and reproduction.

The brain is a potent chemical factory, producing peptides that act as neurotransmitters and neuromodulators that bind to receptors on neurons and act to either excite or inhibit neuron firing. A few examples of natural peptides and related molecules are Dopamine, a pleasure/reward transmitter and pain supresser; Epinephrine, a stress or threat transmitter; Bradykinin, a pain transmitter; and Oxytocin, a regulator of approach-avoidance behavior, promoting "tend and befriend" rather than "fight or flight". Oxytocin is sometimes called the "trust" or "love" hormone because it plays a primary role in sexual and maternal bonding.

Most people think of economic activity as quite cerebral, learned through lengthy education and shaped by culture. If the brain is the hardware, then the utilitarian calculus might be pictured as software, an operating system that is stored and run at various, possibly relocatable hardware sites, and modified by experience and selection. In this view, monitoring the brain can tell you something about the burden the software places on the hardware, but relatively little about what the software is doing. However, the picture that is now emerging is that economic behavior, like the brain itself, has layers, and high-level cognitive activities may appropriate primitive reward pathways to control behavior. Working a spreadsheet to balance a retirement portfolio is indeed a high-level, learned skill. However, economic trading also seems to involve relatively primitive circuits in the limbic system. An evolutionary tale, adapted from Ridley (1996) and Barrett and Fiddick (1999) suggests why this may be so. 
A few million years ago, the great apes had established family structures that were successful in the essentials, obtaining food, protecting themselves from predators, and reproducing. In common with other animals, they evolved a sense of personal space sufficient to provide some defense against attack, and a system of trust that allowed them to get close to family members. These spatial, interactive activities had a physiological basis - neuromodulators and reward pathways in the brain that facilitated these interactions. Some of these apes discovered that through division of labor, specialization, and trade, they could be more successful in surviving and reproducing. But trade, particularly outside the family, was iffy business. To get close enough to a stranger to trade flints for hides, one had to risk being attacked. The apes who were able to form bonds of trust over larger social groups than the family were the most successful at this. These interactions were facilitated by adapting the brain's visceral reward pathways that already functioned in family units. In addition, these apes developed analytic and communication skills, such as language and empathetic attribution of sentiment, that allowed them to operate in larger social and economic groups. These were cerebral activities, and evolution selected the apes with more cerebral capacity.

Among these apes were our ancestors. They gave us large brains, with the capacity to explore the corners of our universe, and to engage in sophisticated economic activities. They also gave us an emotional reward system that processes economic actions in much the same way that it processes personal interactions: when to trust, when to form personal or professional bonds. Therefore, you should not be surprised to learn that brain hardware, the limbic system and its reward pathways, are associated with economic decisions in a substantial and relatively direct way. In particular, the ventral tegmental dopamine reward pathway in the amygdala qualifies as the brain's primary center for recording pleasure, and appears to be active when we are involved in matters of threat, trust, sex, and economic trade.

Much of the information on the neurological foundations of economic behavior comes from measuring brain activity through levels of cellular energy consumption, using imaging techniques such as functional MRI and PET scans. Used in combination with experimental treatments with electrical probes, neurotransmitters, and neuromodulators, and experimental presentation of economic decision-making tasks in games or markets, one has a powerful tool for detecting the links between choice and sensations of pleasure or pain. Brain-damaged humans and animals allow imaging under conditions under which some brain pathways are blocked. However, the linkages from physiological sensation to conscious interpretation and reasoning may be complex, and physiology may give an incomplete picture, just as computer hardware monitoring gives an incomplete picture of what software is doing. Nevertheless, it should be clear than any ability to measure directly in the brain the impact of economic choice tasks on reward pathways is potentially an immensely powerful tool for linking economic activities and consumer 
well-being. I will outline a scattering of results from human and animal studies that provide an intriguing picture of how sensation is directly influenced by economic tasks.

VII.3.1. How do organisms process sensations of pleasure and pain? The answer goes directly to the question of whether there is a single, absolute physiological scale of well-being, and whether the organism consciously or unconsciously acts out of self-interest to maximize this quantity; see Berridge (2003), Bhatt and Camerer (2005). Bozarth (1994), Camerer (2005), Damasio (2005). First, both behavioral observation and brain studies indicate that organisms seem to be on a hedonic treadmill, quickly habituating to homeostasis, and experiencing pleasure from gains and pain from losses relative to the reference point that homeostasis defines; see Sanfey et al (2003). People quickly grow to accept the city in which they are located, their job, their mate, and their health status. They may recognize and complain about unfavorable absolute states, but their levels of satisfaction by various measures are not nearly as differentiated as they would have to be if their sensation of well-being was experienced on an absolute scale. For example, Inglehart (2004) plots country means of self-rated happiness against income. There are obviously major measurement issues associated with such a study, beginning with the difficulty of rendering comparable semanic scales in different languages, but the study's conclusion that money does not buy proportionate happiness is consistent with both the hedonic treadmill and with the proposition that effects other than market goods enter utility.

Second, the picture that emerges from brain studies is that the ventral tegmental dopamine pathways in the limbic/amygdala region play a central role in experiencing pleasure, and also mitigate, with a lag, the sensation of pain; see Becerra et al (1999), McCabe et al (2001), McClure et al (2004), Rustichini et al (2003), Dichhaut et al (2005), Camerer (2005), Glimcher et al (2005, 2009). Adaptation to homeostasis and differentiation between the pleasure and pain circuits coincide with the powerful endowment and loss aversion effects, and sensitivity to framing and context, found in behavioral studies, and suggest that these phenomena are tied fundamentally to brain structure. This is good news and bad news for utilitarians: the limbic system reward pathways seem to correspond to a utility pump, but specialized brain circuitry processes experience in ways that are not necessarily consistent with relentless maximization of hedonic experience.

VII.3.2. Ivan Diamond, a neurologist at the University of California, San Francisco who studied ethanol addiction, found that this and other substance addictions worked primarily by stimulating ventral tegmental dopamine pathways, although addiction once established has other physiological effects; see Diamond and Gordon (1997), Appel et al (2004). His laboratory engineered neuromodulators that block 
the D2 dopamine receptors in this reward pathway; these may lead to effective therapies for ethanol addiction. I cite this work because it shows, indirectly, the close relationship between these reward pathways and economic behavior: Diamond and his colleagues operated an experimental bar in which the spending rate was observed for alcoholics treated with various blockers; this rate was a very good predictor for the efficacy of the blocker.

VII.3.3. David Laibson and colleagues (McClure et al, 2004) have investigated the processing of intertemporal choices. They find that choices involving delayed gratification are primarily processed in the frontal system, and those involving immediate gratification are primarily processed in the limbic system. Thus, eating a candy bar now activates the limbic pleasure center of the brain, deciding to delay gratification requires thought. Unless these systems work together in harmony, time-inconsistent behavior results.

VII.3.4. One of the interesting bits of contemporary biology has been the establishment for a variety of species of simple direct links from particular genes to the production of and receptors for specific neurotransmitters, and from this to specific social behavior. Specific genes control the production and efficacy of the peptide oxytocin in the brain, and this in turn appears to control sexual attraction and behavior in everything from fruit flies to voles to humans. One may ask why these biological findings have any relevance to our discipline. The answer is that sexual reproduction requires close interaction between organisms, and to achieve such interaction requires a suspension of distrust. The oxytocin peptide appears to have the genetic role of promoting trust and bonding between the sexes. This is relevant to economics because trade, and more generally interactions in economic games, also involve elements of trust; see Kosfeld et al (2005), Eisenberger and Lieberman (2004). Thus, in its fundamentals, the primitives of economic behavior and sexual behavior may be the same neurotransmitters and reward pathways in the brain - shopping and sex share the same Dopamine reward pathways.

In a study that strikes at the heart of consumer sovereignty, Ernst Fehr and associates (2005) administer oxytocin or a placebo to subjects, and then ask them to play the trust game. In this game, an investor is given $100 \mathrm{MU}$, and has the option of placing Y MU with an anonymous trustee, who then receives triple this amount, and then chooses to send Z MU back to the investor. The trustee's game is a dictator game in which norms of fairness and reputation matter, but the rational response in a single-shot anonymous game is to return nothing. By backward induction, the investor should send nothing. In fact, both the investment and the return are usually positive, with the level of investment higher in subjects who are administered the "trust" peptide oxytocin. However, oxytocin has no effect on play of the dictator sub-game, where trust 
does not matter. The conclusion is that economic perceptions and decisions are sensitive to brain chemistry, and susceptible to chemical manipulation.

\section{The Future}

What are the challenges and measurement opportunities in the future of research on consumers' economic behavior and well-being? Even from a neoclassical perspective, the role of experience and memory on perceptions and preferences, non-linear budget sets, household production, and hedonics complicate the identification of utility and well-being, but also offer new measurement opportunities, through the added information contained in choice in nonlinear budget sets, and through natural and designed experiments that alter household production possibilities. New results challenge the standard assumption of maximization of individualistic utility, indicating that social networks as information sources, reciprocity, and altruism enter human behavior and cannot be ignored. There are new opportunities to study the sociality of choice through experiments that manipulate the information provided through social networks, the effect of approval, and, through comparative study of isolated societies, the role of cultural and social norms. Finally, the striking ties between brain physiology and behavior in economic decisions, and new methods for measuring and manipulating brain activity, offer the possibility of powerful experiments in which economic, social, and physiological treatments are employed to identify and isolate the causal foundations of economic choice behavior. In particular, the "warm glow" attached to bonding and trust in family and social groups seems to be tied to reward pathways in the limbic system that we experience as pleasure. It may be this chemistry that has worked with selection to promote social cognition and empathy in humans, giving them the mental capacity to function as social animals in large groups, to organize complex and productive economic systems, and to internalize cultural norms for reciprocity, trust, fairness, and altruism.

The challenge facing economic consumer theory is to utilize the disparate measurements and experimental methods that have become available to synthesize a new behavioral science of pleasure that retains the quantitative, predictive features of neoclassical theory in the economic settings where it works well, and extends these features into areas of individual sensation of well-being and choice in the context of social network information and approval, so that the theory can better predict the impact of novel economic policies on consumer well-being. 


\section{References}

Afriat, S.N. (1967) “The construction of utility functions from expenditure data," International Economic Review, 8, 67-77.

Anderson, Simon; A. de Palma; J. Thisse (1992) Discrete choice theory of product differentiation, Cambridge: MIT Press.

Antonelli, G. (1886) "Sulla teoria matematica della economia politica," Nella tipografia del Folchetto, Pisa.

Appel, W., M. McBride, M Diana, I Diamond, A Bonci, (2004) "Ethanol Effects on Dopaminergic "Reward" Neurons in the Ventral Tegmental Area and the Mesolimbic" Alcoholism: Clinical \& Experimental Research, 2004

Arrow, Kenneth, H. Chenery, B. Minhas, R. Solow (1961) “Capital-Labor Substitution and Economic Efficiency,” Review of Economics and Statistics, 43, 225-250.

Arrow, Kenneth (1971) "Exposition of the Theory of Choice Under Uncertainty," Essays on the Theory of Rosk-Bearing, New York: Macmillan, Chap. 2.

Attanasio, O.; N. Pavoni (2011) "Risk Sharing in Private Information Models with Asset Accumulation: Explaining the Excess Smoothness of Consumption,” Econometrica, 79, 1027-1068.

Auspitz, Rudolph and R. Lieben (1889) Untersuchungen uber die Theorie des Prices, Leipzig: Verlag von Duncker \& Humblot.

Barrett, Clark, L. Fiddick (1999) “Evolution and Risky Decisions,” Trends in Cognitive Science, 4, 251-252.

Becerra, Limo, Hans C. Breiter, Milan Stojanovic, Scott Fishman, Annabel Edwards, Alison R. Comite,, R. Gilberto Gonzalez,, David Borsook (1999) "Human brain activation under controlled thermal stimulation and habituation to noxious heat: An fMRI study,” Magnetic Resonance in Medicine, 41, 1044 - 1057

Becker, Gary (1976) “Altruism, Egoism, and Genetic Fitness: Economics and Sociobiology,” Journal of Economic Literature, 14, 817-826.

Bentham, Jeremy (1789) An introduction to the principles of morals and legislation, reprintd by Oxford: The Clarendon press, 1876.

Berridge, Kent (2003) "Pleasures of the Brain,” Brain and Cognition, 52, 105-128.

Berry, Steve; J. Levinsohn; A. Pakes (1995) "Automobile Prices in Market Equilibrium," Econometrica. 63, 841-90.

Berry, Steve; J. Levinsohn; A. Pakes (2004) "Differentiated Products Demand Systems from a Combination of Micro and Macro Data: The New Car Market," Journal of Political Economy. 112, 68-105.

Berry, Steve; O. Linton; A. Pakes (2004) "Limit Theorems for Estimating the Parameters of Differentiated Product Demand Systems," Review of Economic Studies. 71, 613-54.

Bhatt, Meghana, Camerer, Colin F., (2005) "Self-referential Thinking and Equilibrium as States of Mind in Games: fMRI Evidence" . Games and Economic Behavior, 52, 424-459.

Blackorby, Charles; E. Diewert (1979) "Expenditure Functions, Local Duality, and Second Order Approximations," Econometrica, 47, 579-601.

Block, H., J. Marschak (1960) "Random Orderings and Stochastic Theories of Response," in I. Olkin (ed) Contributions to Probability and Statistics, Stanford: Stanford University Press.

Blundell, Richard; J. Powell (2004) "Endogeneity in Semiparametric Binary Response Models," Review of Economic Studies, 71, 655-79.

Blundell, Richard; Browning, Martin; Crawford, Ian (2008) "Best Nonparametric Bounds on Demand Responses," Econometrica 76. 6: 1227-1262.

Blundell, R; Browning, M; Cherchye, L J H; Crawford, I; Rock, B de; Vermeulen, F M P (2012) "Sharp for SARP: Nonparametric Bounds on the Behavioural and Welfare Effects of Price Changes," Tilburg University, Center for Economic Research.

Bowles, Sam and H. Gintis (2011) A Cooperative Species: Human Reciprocity and Its Evolution, Princeton University Press: Princeton.

Bozarth, Michael (1994) "Pleasure Systems in the Brain," in D.M. Warburton (ed.), Pleasure: The politics and the reality, Wiley.

Bridges, D. (1988) "The Euclidean Distance Construction of Order Homeomorphism," Mathematical Social Sciences, 15, 179-188.

Browning, Martin (1991) "A Simple Nonadditive Preference Structure for Models of Household Behavior over Time," The Journal of Political Economy, 99, 607-637.

Campbell, J.; A. Deaton (1989) “’”Why is Consumption So Smooth?” The Review of Economic Studies, 56, 357-74. 
Camerer, Colin, R. Thaler (1995) “Anomalies: Ultimatums, Dictators, and Manners,” Journal of Economic Perspectives, 9, 209-219.

Camerer, Colin (1999) "Behavioral Economics: Reunifying Psychology and Economics,” PNAS, 96, 10575-77.

Camerer, Colin (2005) "Strategizing in the Brain," Science, 300.

Carson, Richard, N. Flores, N. Meade (2001) “Contingent Valuation: Controversies and Evidence,”, Environmental and Resource Economics, 19, 173-210.

Chipman, John; J. Moore (1980) "Compensating Variation, Consumer's Surplus, and Welfare," American Economic Review. 70: 933-49

Chipman, John; J. Moore (1990) "Acceptable Indicators of Welfare Change, Consumer's Surplus Analysis, and the Gorman Polar Form," in D. McFadden, M. Richter (eds) Preferences, uncertainty, and optimality: Essays in honor of Leonid Hurwicz. Boulder and Oxford: Westview Press; 68-120

Christensen, Laurits; D. Jorgenson,; L. Lau (1975) "Transcendental Logarithmic Utility Functions," American Economic Review. 65: 367-83

Conniffe, Denis (2007) “A Note on Generating Globally Regular Indirect Utility Functions," B.E. Journal of Theoretical Economics, 7.1, 1-11.

Court, Andrew (1939) "Hedonic Price Indexes with Automobile Examples," in General Motors Corp. The Dynamics of Automobile Demand, New York: General Motors Corp., pp. 99-117.

Dagsvik, J.; S. Strom, Z. Zia (2005) "Utility of Income as a Random Function: Behavioral Characterization and Empirical Evidence," Statistics Norway, Working Paper.

Damasio, Antonio (2005) "Brain Trust," Nature, 435.

Deaton, Angus; J. Muellbauer (1980a) "An Almost Ideal Demand System," American-Economic-Review. 70, 312-26

Deaton, Angus, John Muellbauer (1980b) Economics and Consumer Behavior, Cambridge Univ. Press.

Debreu, Gerard (1959) Theory of Value, New Haven : Yale University Press.

Debreu, Gerard (1974) "Excess Demand Functions,” Journal of Mathematical Economics, 1, 15-24.

Debreu, Gerard (1986) "Topological Methods in Cardinal Utility Theory," Mathematical economics: Twenty papers of Gerard Debreu, Econometric Society Monograph. Cambridge; New York and Melbourne: Cambridge University Press,

Diamond, Ivan, A. Gordon (1997) “Cellular and molecular neuroscience of alcoholism,” Physiological Review, 77.

Diamond, P.; Hausman, J. \{1994) "Contingent Valuation: Is Some Number Better than No Number?" Journal of Economic Perspectives; 8, 45-64.

Dickhaut, John, K. McKabe, J. Nagode, A. Rustichini, K. Smith, J. Pardo (2005) “The Impact of Certainty Context on the Process of Choice," University of Minnesota working paper.

Diewert, Erwin (1971) "An Application of the Shephard Duality Theorem, a Generalized Leontief Production Function," Journal of Political Economy, 79, 481-507.

Diewert, Irwin (1974) “Applications of duality theory,” in M. Intriligator and D. Kendrick (eds) Frontiers of Quantitative Economics, II, Amsterdam: North-Holland, 106-71.

Diewert, Irwin (1982) "Duality approaches to microeconomic theory," in K.J. Arrow and M.D. Intriligator (eds) Handbook of Mathematical Economics, II, Amsterdam: North-Holland, 535-99

Domemcich, Thomas, D. McFadden (1975) Urban Travel Demand: A Behavioral Analysis, North Holland: Amsterdam.

Dubin, Jeffrey,, D. McFadden (1984) "An Econometric Analysis of Residential Electric Appliance Holdings and Consumption," Econometrica, 52, 345-62

Dupuit, Jules (1844) "On the Measurement of the Utility of Public Works", Annales des ponts et chaussées. (English translation, International Economic Review, 1952).

Edgeworth, Francis Y. (1881) Mathematical Psychics; an essay on the application of mathematics to the moral sciences, London, C. K. Paul \& co.

Edgeworth, Francis Y. (1894) "Distance in Time as an Element of Value," Palgrave's Dictionary of Political Economy. Republished in P. Newman, F. Y. Edgeworth's Mathematical Psychics and Further papers on Political Economy, Oxford: Oxford University Press, 2003.

Eisenberger, Naomi, M. Lieberman (2004) "Why rejection hurts: a common neural alarm system for physical and social pain,” Trends in Cognitive Science, 8, 294-300.

Ekeland, Ivar (2010) "Existence, Uniqueness, and Efficiency of Equilibrium in Hedonic Markets with Multidimensional Types,” Economic Theory, 42, 275-315.

Fisher, Irving (1892) Mathematical Investigations in the Theory of Value and Prices, Yale. 
Fisher, Irving (1908) "Are Savings Income?" American Economic Association Quarterly, 3rd Series, 9, 21-47.

Fisher, Irving (1918) "Is 'utility' the Most Suitable Form for the Concept it is Used to Denote?" American Economic Review, 8, 335-337.

Fisher, Irving (1927) "A Statistical Method for Measuring Marginal Utility and Testing for the Justice of a Progressive Income Tax," in J. Hollander (ed) Economic Essays in Honor of John Bates Clark, New York Macmillan.

Fisher, Irving (1930) The theory of interest as determined by impatience to spend income and opportunity to invest it, New York, The Macmillan Company.

Fehr, Ernst, S. Gachter (2002) “Altruistic Punishment in Humans,” Nature 415, 137-140.

Fehr, Ernst, U. Fischbacher (2002) "Why Social Preferences Matter - The Impact of Non-selfish Motives on Competition, Cooperation, and Incentives,” The Economic Journal, 112, 1-33.

Fehr, Ernst, U. Fischbacher, M. Kosfeld (2005) "Neuroeconomic Foundations of Trust and Social Preferences," American Economic Review, 95, 346-351.

Fenchel, W. (1953) Convex Cones, Sets, and Functions: Lecture Notes, Princeton University mimeograph.

Fosgerau, Mogens, D. McFadden (2012) "A theory of the perturbed consumer with general budgets," working paper.

Frey, Bruno and A. Stutzer (2002a) "The Economics of Happiness,” World Economics, 1-17.

Frey, Bruno and A. Stutzer (2002b) Happiness and Economics, Princeton University Press.

Frisch, Ragnar (1926) "Sur un Probleme of Economie Pure," Norsk Matematisk Forenings SSkrifter, 16, 1-40; Translation in J. Chipman, L. Hurwicz, M. Richter, and H. Sonnenschein (eds) Preferences, Utility, and Demand, New York: Harcourt.

Frisch, Ragnar (1932) New Methods of Measuring Marginal Utility, Tubingen, Mohr.

Fuss, Mel, D. McFadden (1978) Production Economics: A Dual Approach to Theory and Applications, North Holland: Amsterdam.

Gilovich, Thomas, D. Griffin, D. Kahneman (2002) Heuristics and Biases: The Psychology of Intuitive Judgment, Cambridge.

Glimcher, Paul, M. Dorris, H. Bayer (2005) “Physiological utility theory and the neuroeconomics of choice,” Games and Economic Behavior, 52, 213-256.

Glimcher, Paul, E. Fehr, C. Camerer, R. Poldrack, eds. (2009) Neuroeconomics: Decision Making and the Brain, Academic Press: New York.

Georgescu-Roegen, Nicholas. 1936. “The Pure Theory of Consumer’s Behavior,” Quarterly Journal of Economics 50.4: 545-93.

Gorman, W. (1953) “Community Preference Fields,” Econometrica, 21, 63-80.

Gorman, W. (1961) "On a Class of Preference Fields,” Metroeconomica, 13, 53-56.

Gossen, Hermann (1854) Die Entwicktlung, English translation: The Laws of Human Relations, Cambridge: MIT Press, 1983.

Green, Paul, D. Carroll, P. Greem, S. Goldberg (1981) “A general approach to product design optimization via conjoint analysis,” Journal of Marketing, 45, 17-37.

Green, Paul ,A. Krieger, Y. Wind (2001) “Thirty Years of Conjoint Analysis: Reflections and Prospects,” Interfaces 31, S56-S73.

Green, Donald, K. Jacowitz,, D. Kahneman, D. McFadden (1998) "Referendum Contingent Valuation, Anchoring, and Willingness to Pay for Public Goods," Resource and Energy Economics, 20, 85- 116.

Griliches, Zvi., I. Adelman (1961) “On an Index of Quality Change,” Journal of the American Statistical Association, 56, 535-548.

Hall, R. E. (1978), "Stochastic Implications of the Permanent Income Hypothesis: Theory and Evidence," Journal of Political Economy, 96: 971-987.

Hamilton, William (1964). "The genetical evolution of social behaviour". Journal of Theoretical Biology 7: 1-52.

Hammond, Peter (1994) "Money Metric Measures of Individual and Social Welfare Allowing for Environmental Externalities," in W. Eichhorn (ed) Models and Measurement of Welfare and Inequality, Springer-Verlag, 694-724.

Hastie, Reid, R. Dawes (2001) Rational Choice in an Uncertain World, Sage.

Hausman, Jerry (1985) "The Econometrics of Nonlinear Budget Sets," Econometrica, 53, 1255-82

Heckman James J, Rosa Matzkin and Lars Nesheim (2010), "Nonparametric Identification and estimation of nonadditive hedonic models," Econometrica, 78, 1569-91.

Henrich, Joseph, R. Boyd, S. Bowles, C. Camerer, E. Fehr, H. Gintis (2004) Foundations of Human Sociality, Oxford University Press.

Hicks, John (1939) Value and Capital, Oxford, Clarendon press. 
Horowitz, Joel; N. Savin (2001) "Binary Response Models: Logits, Probits and Semiparametrics,"Journal of Economic Perspectives. 15, 43-56

Horowitz, Joel (1992) “A Smoothed Maximum Score Estimator for the Binary Response Model,” Econometrica, 60, 505-31

Hotelling, Harold (1935) "Demand Functions with Limited Budgets,” Econometrica, 3, 66-78.

Houthakker, Hendrik (1950) "Revealed Preference and the Utility Function," Economica, 17, 159-174.

Huang, Ju Chin; D. Nychka (2000) "A Nonparametric Multiple Choice Method within the Random Utility Framework,” Journal of Econometrics. 97, 207-25

Huber, Joel, J. Lynch, K. Corfman, J. Feldman, M. Holbrook, D. Lehman, B. Munier, D. Schkade, I. Simonson (1997) "Thinking about values in prospect and retrospect: maximizing experienced utility," Marketing Letters, 8, 323-334.

Hurwicz, Leonid, H. Uzawa (1971) "On the Integrability of Demand Functions," in J. Chipman, L. Hurwicz, M. Richter, and H. Sonnenschein (eds) Preferences, Utility, and Demand, New York: Harcourt, 114-148.

Ichimura, Hidehiko; L. F. Lee (1991) "Semiparametric Least Squares Estimation of Multiple Index Models: Single Equation Estimation," in W. Barnett, J. Powell,, G. Tauchen, (eds). Nonparametric and semiparametric methods in econometrics and statistics: Proceedings of the Fifth International Symposium in Economic Theory and Econometrics. Cambridge; Cambridge University Press; 3-49

Ichimura, Hidehiko; T. S. Thompson (1998) "Maximum Likelihood Estimation of a Binary Choice Model with Random Coefficients of Unknown Distribution,” Journal of Econometrics. 86: 269-95.

Inglehart, Ronald (2004) European and World Value Surveys Integrated Data File, 1999-2002, Ann Arbor: Institute for Social Research, University of Michigan.

Jevons, William (1871) Theory of Political Economy, reprinted by London, Macmillan, 1931.

Johansson-Stenman, H. Svedsater (2003) "Self-Image and Choice Experiments: Hypothetical and Actual Willingness to Pay,” working paper, Goteborg University.

Johnson, Richard (1974) "Trade-off analysis of consumer values," Journal of Marketing Research, 11, 121-127.

Jorgenson, Dale; L. Lau,; T. Stoker (1980) "Welfare Comparison under Exact Aggregation," American Economic Review, 70: 268-72

Jorgenson, Dale; L. Lau; T. Stoker (1997) "The Transcendental Logarithmic Model of Aggregate Consumer Behavior," in D. Jorgenson (ed) Welfare. 1. Aggregate consumer behavior. Cambridge and London: MIT Press; 203-356. Previously published: 1982.

Kahneman, D.; Knetsch, J.; Thaler, R. (1990) "Experimental Tests of the Endowment Effect and the Coase Theorem," Journal of Political Economy 98, 1325-1348.

Kahneman, D.; Knetsch, J.; Thaler, R. (1991) "The Endowment Effect, Loss aversion, and Status Quo bias," Journal of Economic Perspectives 5, 193-206.

Kahneman, Daniel, P. Wakker, R. Sarin (1997) "Back to Bentham? Explorations of Experienced Utility,” The Quarterly Journal of Economics, 112, 375-405.

Kahneman, Daniel, E. Diener, N. Schwartz (1999) Well-Being: The Foundations of Hedonic Psychology, Sage.

Katzner, Donald (1970) Static Demand Theory, New York: Macmillan.

King, Gary, C. Murray, J. Salomon, A. Tandon (2004) "Enhancing the Validity and Cross-Cultural Comparability of Measurement in Survey Research,” American Political Science Review, 98, 191-207.

Knetsch, Jack (1989) "The Endowment Effect and Evidence of Nonreversible Indifference Curves," American Economic Review, 79, 1277-1284.

Kohler, Hans-Peter (2001) Fertility and Social Interactions, Oxford University Press.

Kosfield, Michael, M. Heinrichs, Paul Zak, U. Fischbacher, E. Fehr (2005) “Oxytocin increases trust in humans," Nature, 435.

Koszegi, Botond (2004) "Ego Utility, Overconfidence, and Task Choice," Journal of the European Economics Association, 4, 673-707.

Lancaster, Kevin (1966) “A New Approach to Consumer Theory,” Journal of Political Economy, 132-157.

Langer, Thomas, M. Weber (2001) "Prospect Theory, Mental Accounting, and Differences in Aggregated and Segregated Evaluation of Lottery Portfolios,” Management Science 47, 716-733.

Lewbel, Arthur (1992) "Aggregation with Log-Linear Models," Review of Economic Studies, 59: 635-42.

List, John (2004) "Neoclassical Theory versus Prospect Theory: Evidence from the Marketplace," Econometrica, 72, $615-25$ 
Lowenstein, George (1996) “Out of Control: Visceral Influences on Behavior," Organizational Behavior and Human Decision Processes, 65, 272-292.

Lowenstein, George, D. Read, R. Baumeister (2003) Time and Decision: Economic and Psychological Perspectives on Intertemporal Choice, Sage.

Lucas, Robert (1975) "An Equilibrium Model of the Business Cycle," The Journal of Political Economy. 83, 1113-1144.

Luce, Duncan, John Tukey (1964) “Simultaneous conjoint measurement: A new type of fundamental measurement," Journal of Mathematical Psychology, 1, 1-27.

Luce, R., P. Supes (1965) "Preference, Utility, and Subjective Probability," in R. Luce, R. Bosh, and F. Galanter (eds) Handbook of Mathematical Psychology, 3, New York: Wiley.

Malinvaud, E. (1953) "Capital Accumulation and Efficient Allocation of Resources," Econometrica, 21, 233-268.

Manski, Charles (1991) "Nonparametric estimation of expectations in the analysis of discrete choice under uncertainty," in W. Barnett, J. Powell, and G. Tauchen (eds) Nonparametric Methods in Econometrics and Statistics, Cambridge University Press, 259-275.

Manski, Charles (1993) “Dynamic Choice in Social Settings: Learnings from the Experiences of Others,” Journal of Econometrics. 58: 121-36.

Manski, Charles (2004) "Measuring Expectations,” Econometrica, 72, 1329-1376.

Marschak, J. (1960) "Binary Choice Constraints on Random Utility Indicators," in K. Arrow (ed) Stanford Symposium on Mathematical Methods in the Social Sciences, Stanford: Stanford University Press.

Marshall, Alfred (1895) Principles of economics, London ; New York : Macmillan.

Mas-Colell, Andreu; M. Whinston, and J. Green (1995) Microeconomic Theory, Oxford: Oxford University Press.

Mas-Colell, Andreu (1996) "A model of equilibrium with differentiated commodities," in G. Debreu (ed) General Equilibrium Theory, 2, Elgar: Cheltenham, 462-494.

Matzkin, Rosa (1992) "Nonparametric and Distribution-Free Estimation of the Binary Threshold Crossing and the Binary Choice Models," Econometrica, 60, 239-70

Matzkin, Rosa (1993) "Nonparametric Identification and Estimation of Polychotomous Choice Models," Journal of Econometrics, 58, 137-68.

Matzkin, Rosa (2005) "Identification of consumers' preferences when their choices are unobservable,” Economic Theory, 26, 423-444.

Matzkin, Rosa (2008) “Identification in Nonarametric Simultaneous Equations Models,” Econometrica, 76, 945-978.

Matzkin, Rosa (2012) "Identification in Nonparametric Limited Dependent Variable Models with Simultaneity and Unobserved Heterogeneity," Journal of Econometrics, 166, 106-115.

Matzkin, Rosa and D. McFadden (2011) “Trembling Payoff Market Games,” working paper.

McCabe, Kevin, Daniel Houser, Lee Ryan, Vernon Smith, and Theodore Trouard (2001) "A functional imaging study of cooperation in two-person reciprocal exchange," PNAS, 98, 11832-5.

McClure, S. M., D. Laibson, G. Lowenstein, J. Cohen (2004) "Separate neural systems value immediate and delayed monetary rewards,” Science, 306.

McFadden, Daniel (1966) “Cost, Revenue, and Profit Functions,” Univ. of California lecture notes.

McFadden, Daniel (1974a) “Conditional Logit Analysis of Qualitative Choice Behavior,” in P. Zarembka (ed) Frontiers of Econometrics, Academic Press: New York, 105-142.

McFadden, Daniel (1974b) "The Measurement of Urban Travel Demand,” Journal of Public Economics, 3, 303-328.

McFadden, Daniel (1974c) "On Some Facets of Betting," in M.S. Balch, D. McFadden, and S.Y. Wu (eds.), Essays on Economic Behavior under Uncertainty, North-Holland: Amsterdam, 126-137.

McFadden, Daniel, R. Mantel, A. Mas-Colell, and M.K. Richter (1974) "A Characterization of Community Excess Demand Functions," Journal of Economic Theory, 9, 361-374.

McFadden, Daniel (1986) "The Choice Theory Approach to Market Research,” Marketing Science, 275-297.

McFadden, Daniel (1990) "Stochastic Rationality and Revealed Stochastic Preference," with M.K. Richter, in J. Chipman, D. McFadden, and M.K. Richter (eds.), Preferences, Uncertainty, and Optimality: Essays in Honor of Leo Hurwicz, Westview Press: Boulder, CO, 161-186.

McFadden, Daniel (1994) "Contingent valuation and social choice," American Journal of Agricultural Economics 76, 689-708.

McFadden, Daniel, K. Train (1996) "Consumers' Evaluation of New Products: Learning from Self and Others," Journal of Political Economy, 104, 683-703.

McFadden, Daniel (1999a) "Rationality for Economists?" Journal of Risk and Uncertainty, 19, 73-105. 
McFadden, Daniel (1999b) "Computing Willingness-to-Pay in Random Utility Models," in J. Moore, R. Riezman, and J. Melvin (eds.), Trade, Theory, and Econometrics: Essays in Honour of John S. Chipman, Routledge: London.

McFadden, Daniel, K. Train (2000) "Mixed MNL Models for Discrete Response," Journal of Applied Econometrics, $15,447-470$.

McFadden, Daniel (2005) "Revealed Stochastic Preference: A Synthesis,” Economic Theory, 26, 245-264.

McFadden, D. (2006) "Free Markets and Fetered Consumers," American Economic Review, 96, 5-29.

McFaden, Daniel (2008) "Environmental Valuation of Environmental Projects," Univ. of California working paper.

McFadden, Daniel (2010) "Sociality, Rationality, and the Ecology of Choice," in Stephane Hess and Andrew Daly (eds) Choice Modelling: The State-of-the-Art and the State-of-Practice, Emerald: Bingley.

McFadden, Daniel (2012) “Economic Juries and Public Project Provision,” Journal of Econometrics, 166, 116-126.

McKenzie, Lionel (1957) "Demand Theory Without a Utility Index," The Review of Economic Studies, 24, 185-189 .

Mellers, Barbara (2000) "Choice and the Relative Pleasure of Consequences," Psychological Bulletin, 126, 910-974.

Morikawa, Takashi; M. Ben-Akiva; D. McFadden (2002) "Discrete Choice Models Incorporating Revealed Preferences and Psychometric Data," in P. Franses and A. Montgomery (eds) Econometric models in marketing. Amsterdam; London and New York: Elsevier Science,; 29-55

Moscati, Ivan (2007) "Early Experiments in Consumer Demand Theory: 1930-1970," History of Political Economy, 39, 359-401.

Muth, John (1992) "Rational Expectations and the Theory of Price Movements," in K. Hoover, ed. The new classical macroeconomics. Vol. 1. Elgar, 3-23. Previously published: 1961.

Muth, John (1994) "Optimal Properties of Exponentially Weighted Forecasts," in A. Harvey, ed. Time series. Vol. 1.. Elgar. 121-28. Previously published: 1960.

Muth, Richard (1998) "Household Production and Consumer Demand Functions," in K. Lancaster,-ed. Consumer theory. Elgar, 302-11. Previously published: 1966.

Myagkov, Mikhail; C. Plott (1997)" Exchange Economies and Loss Exposure: Experiments Exploring Prospect Theory and Competitive Equilibria in Market Environments," American Economic Review. 87, 801-28

Newman, Peter (2003) F.Y. Edgeworth: Mathematical Psychics and further papers on political economy, Oxford.

Ohta, Makoto (1971) Hedonic price index for boiler and turbo-generator: a cost function approach. Ph.D. Thesis, University of California, Berkeley.

Ohta, Makoto, Z. Griliches (1986) “Automobile Prices and Quality: Did Gasoline Pric Increases Change Consumer Tastes in the U.S.?” Journal of Business and Economic Statistics, 4, 187-198.

Okubo, Masakatsu (2008) "Intertemporal Substitution and Nonhomothetic Preferences," Economic Letters, 98, 41-47.

Pagan, Adrian; A. Ullah (1999): Nonparametric econometrics, Cambridge; Cambridge University Press.

Pareto, Vilfredo (1906) Manual of Political Economy, English Translation, Augustus M. Kelley, NY, 1971.

Peleg, B. (1970) "Utility functions for partially ordered topological spaces," Econometrica, 38, 93-96.

Pollack, Robert (1970) "Habit Formation and Dynamic Demand Function," Econometrica, 41, 867-887.

Rabin, Matthew (1998) "Psychology and Economics,” Journal of Economic Literature, 36, 11-46.

Rader, Trout (1973) “Nice demand functions,” Econometrica, 41, 913-935.

Redelmeier, Donald, D. Kahneman (1996) "Patent's memories of painful medical treatments: real-time and retrospective evaluations of two minimally invasive procedures,” Pain, 66, 3-8.

Richter, Marcel K. (1966) "Revealed Preference Theory,” Econometrica, 34, 635-645.

Rosen, Sherwin (1974) "Hedonic Prices and Implicit Markets: Product Differentiation in Perfect Competition," Journal of Political Economy, 82, 34-55.

Rustichini, A., J. Dickhaut, P. Ghirardato, K. Smith, J. Pardo (2003) “A Brain Imaging Study of the Choice Process,” working paper, University of Minnesota.

Ridley, Matt (1996) The Origins of Virtue, Penguin.

Rosen, Sherwin (1974) "Hedonic Prices and Implicit Markets: Product Differentiation in Pure Competition," Journal of Political Economy, 82, 34-55.

Rossi, Peter (1979). Vignette analysis: Uncovering the normative structure of complex judgements. In R. K. Merton \& J. S. Coleman \& P. H. Rossi (Eds.), Qualitative and quantitative social research: Papers in honor of Paul Lazarsfeld (pp. 175-188). New York: Macmillan.

Roy, Rene (1942) Elements d'econometrie. Presses universitaires de France, 1970.

Sanfey, Alan G., James K. Rilling, Jessica A. Aronson, Leigh E. Nystrom, Jonathan D. Cohen, (2003) The Neural Basis of Economic Decision-Making in the Ultimatum Game,” Science, 300, 1755-1758 .

Samuelson, Paul (1947) Foundations of economic analysis, Cambridge: Harvard University Press, 1983. 
Samuelson, Paul (1948) “Consumption theory in terms of revealed preference,” Economica, 15, 243-253.

Samuelson, Paul (1950) "The problem of integrability in utility theory,” Economica, 17, 355-385.

Samuelson, Paul (1993) "Altruism as a problem involving group versus individual selection in economics and biology,” American Economic Review, 83, 143-148.

Savage, L. J. (1954) The Foundations of Statistics, New York, Wiley.

Shephard, Ron (1953) Cost and production functions. Princeton, Princeton University Press,

Signorini, D., M. Jones (2004) "Kernel Estimators for Univariate Binary Regression,” Journal of the American Statistical Association; 99,: 119-26

Slutsky, Eugen (1915) "Sulla teoria del bilancio del consummatore", Giornale degli Economisti. English translation, "On the Theory of the Budget of the Consumer," in G. Stigler and K. Boulding, eds, Readings in Price Theory, Homewood: Irving.

Smith, Adam (1753) The Theory of Moral Sentiments, Oxford University Press, 1984.

Smith, Adam (1776) An inquiry into the nature and causes of the wealth of nations. London, W. Strahan and T. Cadell.

Stone, Richard (1954) "Linear Expenditure Systems and Demand Analysis,” Economic Journal, 64, 511-527.

Sundaresan, Suresh (1989) "Intertemporally Dependent Preferences and the Volatility of Consumption and Wealth," Review of Financial Studies, 2, 75-89.

Taussig, F/ (1912) Principles of Economics, New York: Macmillan.

Taylor, Lester (2005) "Estimation of Theoretically Plausible Demand Functions from U. S. Consumer Expenditure Survey Data," working paper, University of Arizona.

Thurstone, L.L. (1931) “The indifference function,” Journal of Social Psychology, 2, 139-167.

Toubia, Olivier, D. Simester, J. Hauser, E. Dahan (2003) “Fast Polyhedral Adaptive Conjoint Estimation,” Marketing Science, 22, 273-303.

Train, Kenneth, C. Winston (207) "Vehicle Choice Behavior and the Declining Market Share of U.S. Automakers," International Economic Review, 48, 1469-1498.

Urban, Glen. L., John. R. Hauser, and John. H. Roberts (1990), "Prelaunch Forecasting of New Automobiles: Models and Implementation," Management Science, Vol. 36, No. 4, (April), 401-421.

Urban, Glen L., John R. Hauser, William J. Qualls, Bruce D. Weinberg, Jonathan D. Bohlmann and Roberta A. Chicos (1997), "Validation and Lessons from the Field: Applications of Information Acceleration," Journal of Marketing Research, 34, 1, (February), 143-153.

Uzawa, Hirofumi (1971) "Preference and Rational Choice in the Theory of Consumption," in J. Chipman, L. Hurwicz, M. Richter, and H. Sonnenschein (eds) Preferences, Utility, and Demand, New York: Harcourt, 7-28.

Van Praag, Bernard, A. Kapteyn (1994) "How Sensible is the Leyden Individual Welfare Function of Income? A Reply ” International Economic Review, 38, 1817-1825.

Varey, Carol, \& D. Kahneman (1992). "Experiences extended across time: Evaluation of moments and episodes,” Journal of Behavioral Decision Making, 5, 169-186.

Varian, Hal (1982) "The Nonparametric Approach to Demand Analysis," Econometrica, 50: 945-73.

Varian, Hal (1992) Microeconomic Analysis, New York: Norton.

Varian, Hal (2006) Revealed Preference. New York: Oxford University Press.

Von Neumann, John; O. Morgenstern (1953) Theory of games and economic behavior, Princeton, Princeton University Press

Wallis W. Allen, and Milton Friedman (1942) “The Empirical Derivation of Indifference Functions," in O. Lange and others (eds) Studies in Mathematical Economics and Econometrics, Chicago: University of Chicago Press, 175-89.

Willig, Robert (1976) "Consumer's Surplus without Apology," American-Economic-Review. 66: 589-97.

Yatchew, Adonis (1998) "Nonparametric Regression Techniques in Economics," Journal of Economic Literature, 36, 669-721.

Yatchew, Adonis (2003) Semiparametric regression for the applied econometrician, Cambridge, UK ; New York : Cambridge University Press.

Yoon, Kiho (2001) “The Modified Vickery Double Auction,” Journal of Economic Theory, 101, 572-584.

Zamagni, Stefano (1995) The Economics of Altruism, Elgar. 
The New Science of Pleasure - Figures and Tables

Figure 1. Dupuit's Inverse Problem

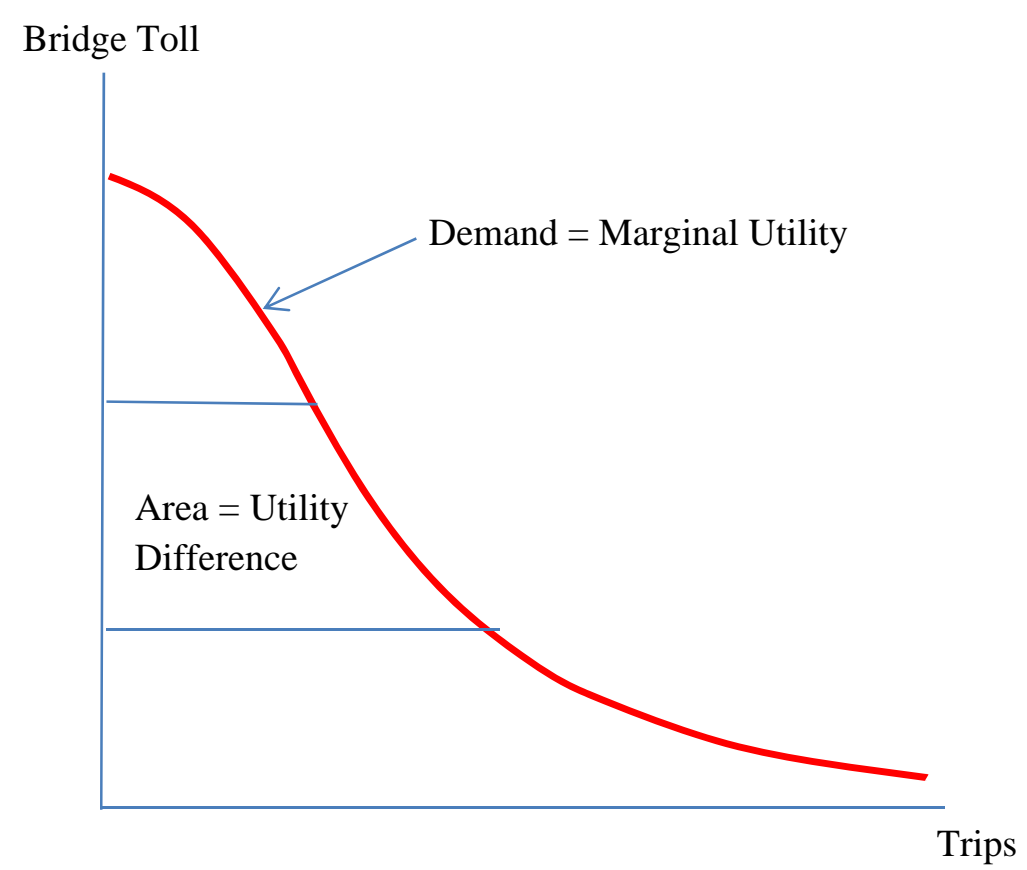


Figure 2. The Extended Neoclassical Model

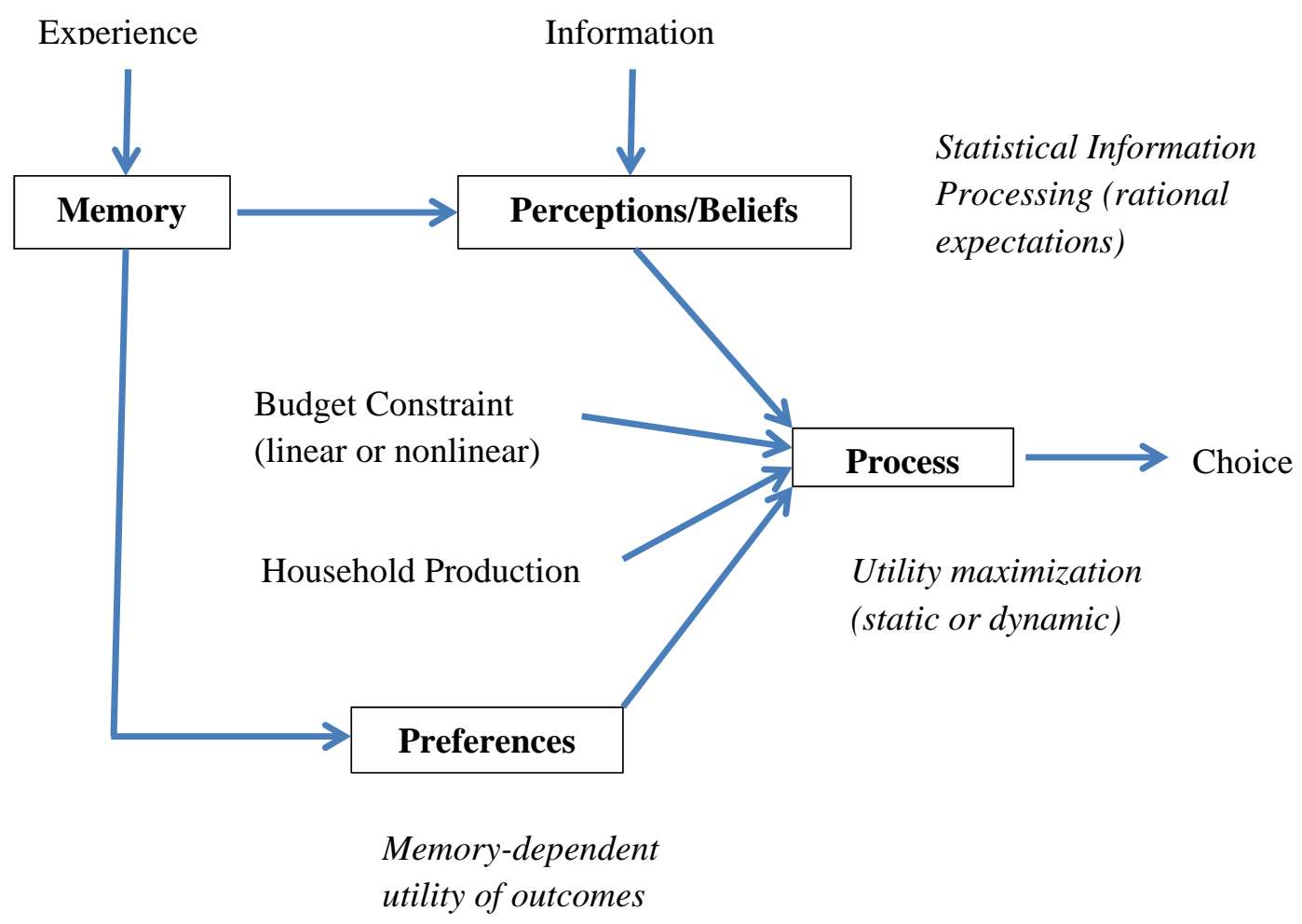


Figure 3. The Behavioral Choice Model

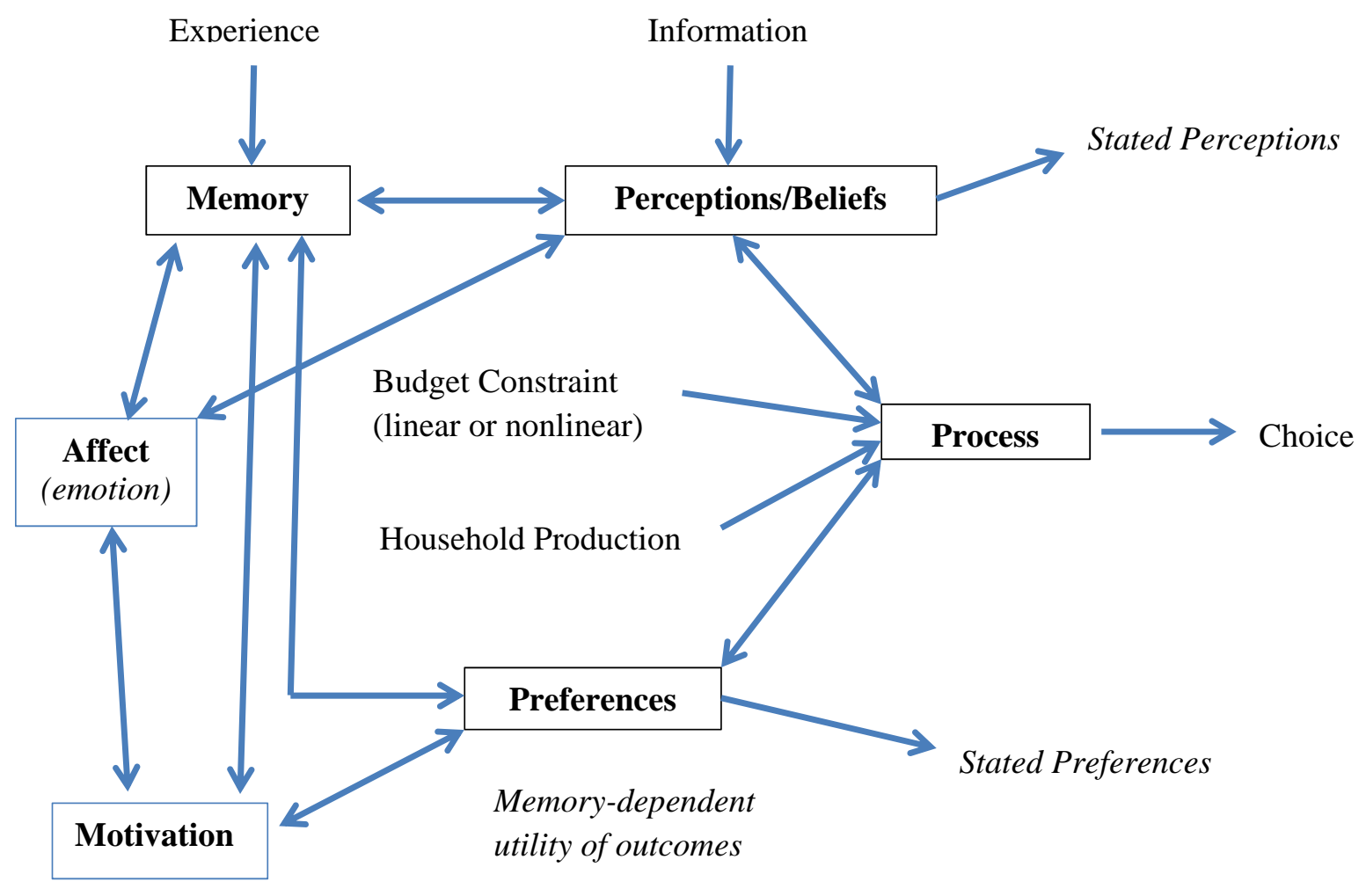


Figure 4. Bids in the Pencil Experiment

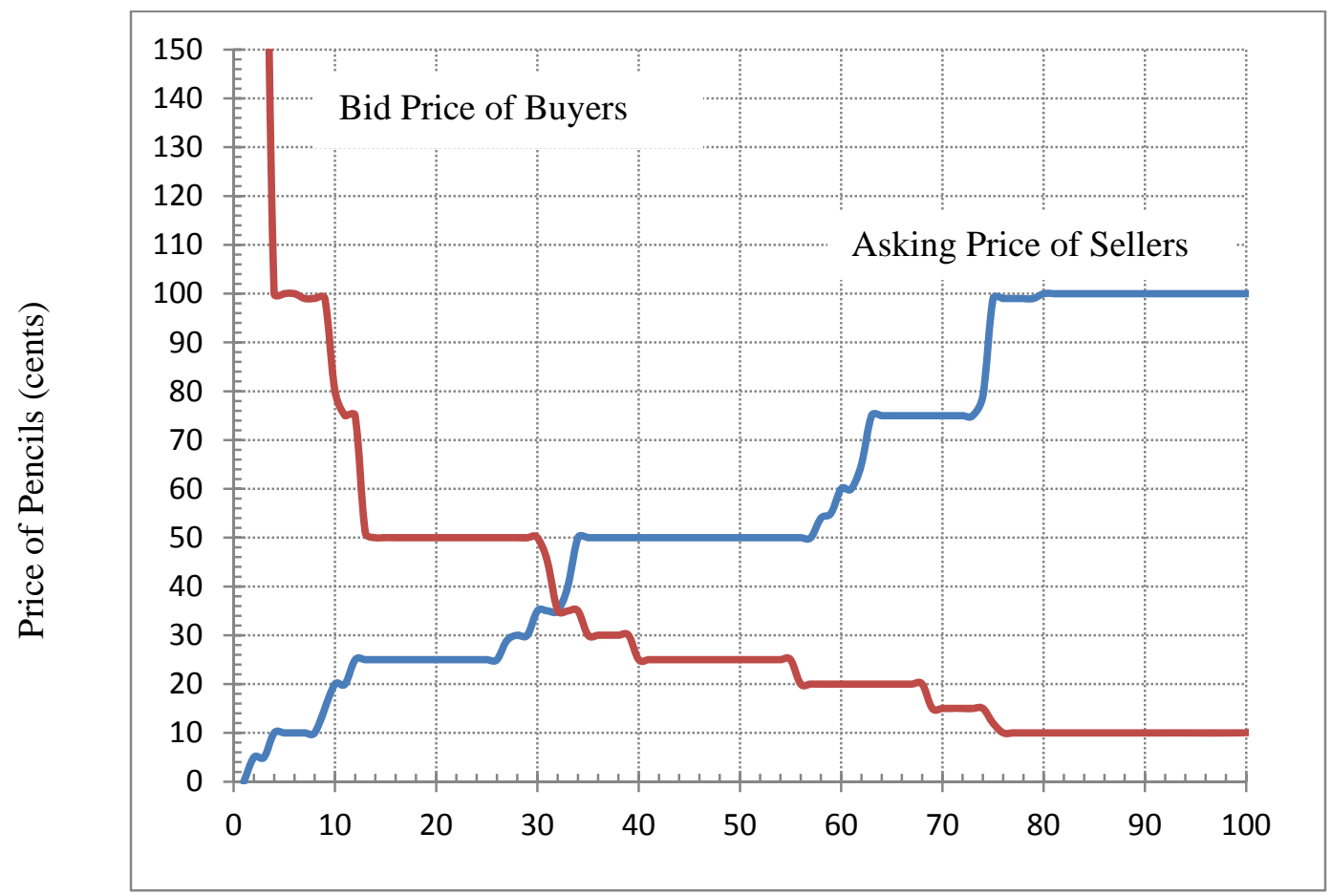

Pencils 


\begin{tabular}{|ccccccccc}
\hline \multicolumn{7}{c}{ Table 1. Price and Total Expenditure Elasticities } \\
\multicolumn{7}{c}{ Almost Ideal Demand System, 1995 CES-ACCRA Surveys, from Lester Taylor (2005) } \\
food & food & shelter & utilities & trans & health & misc & total exp \\
shelter & -0.2981 & 0.6644 & 0.0599 & -0.0013 & 0.1400 & -0.5044 & 0.4469 \\
utilities & -0.1105 & -0.8285 & 0.1909 & 0.1902 & 0.2782 & -0.5777 & 0.8876 \\
trans & -0.1071 & 0.1638 & -0.7222 & 0.0523 & -0.0669 & 0.1783 & 0.4612 \\
health & -0.7813 & -0.2520 & -0.2471 & -1.3739 & -0.7627 & 1.5824 & 1.7250 \\
misc & 0.4395 & -0.2179 & -0.2267 & -0.0154 & 0.0470 & -1.1448 & 1.2150 \\
\hline
\end{tabular}




\section{Table 2. COGNITIVE ANOMALIES}

EFFECT

DESCRIPTION

\section{COMPREHENSION}

Completion/Substitution Missing or ambiguous parts of question are reconstructed

Disjunction

Failure to reason through or accept the logical consequences of choices

Engagement/Awareness

Format/Mode

Limited attention to and engagement in the cognitive task

Construal

Availability influenced by format, visual or auditory presentation

Translation

Question interpreted as one the subject is able (or prefers) to answer

Question terminology translated into subject's personal vocabulary

\section{RETRIEVAL OF FACTUAL AND AFFECTIVE MEMORY}

Affective attenuation

Availability

Primacy/Recency

Reconstructed Memory

Selective Memory

Telescoping/Temporal
Affective memories are recalled with diminished intensity

Memory reconstruction is tilted toward the most available and salient information

Initial and recent experiences are the most available

Imperfect memories rebuilt using contemporary cues and context, historical exemplars, commonly employed search criteria

Coincidences are more available than non-coincidences

Compression and attenuation of history, inconsistent time discounting

\section{JUDGMENT AND THE FORMATION OF PERCEPTIONS AND BELIEFS}

Anchoring

Context/Framing

Endowment

Extension

Prominence/Order

Prospect

Regression

Representativeness
Judgments are influenced by quantitative cues contained in the decision task History and framing of the decision task influence perception and motivation No action is the "safe" choice. "The devil you know is better than the devil you don't"

Representative rates are more available than integrated experience The format or order of decision tasks influences the weight given to different aspects Inconsistent probability calculus, asymmetry in gains and losses

Attribution of causal structure to fluctuations; failure to anticipate regression to mean

Frequency neglect in exemplars

\section{TASK DEFINITION, AND THE DECISION AND REPORTING PROCESSES}

Awareness

Construal/Constructive

Prevarication/Projection

Suspicion/Superstition

Rule-Driven
Recognition of choices, subjective definition of choice set

Cognitive task misconstrued, preferences constructed endogenously

Misrepresentation for real or perceived strategic advantage or to project self-image

Subjects mistrust offers and question motives of others in unfamiliar situations, avoid choices that "tempt fate"

Choice guided by principles, analogies, and exemplars rather than utilitarian calculus; rules induce pro forma, focal responses 


\begin{tabular}{|c|c|c|}
\hline \multicolumn{3}{|c|}{ Table 3. ULTIMATUM GAME OUTCOMES } \\
\hline Society & Mean Offer & Rejection Rate \\
\hline Lamalera (communal hunting village) & $57 \%$ & NC \\
\hline Ache (seasonal foraging band) & $48 \%$ & $0.0 \%$ \\
\hline Hazda (foraging band) & $40 \%$ & $19.2 \%$ \\
\hline Machiguenga (subsistence farming families) & $26 \%$ & $4.8 \%$ \\
\hline
\end{tabular}

